\title{
AN INTEGRATED FUZZY DEMATEL-FUZZY ANP MODEL FOR EVALUATING CONSTRUCTION PROJECTS BY CONSIDERING INTERRELATIONSHIPS AMONG RISK FACTORS
}

\author{
Seyed Morteza HATEFI ${ }^{\circledR}$, Jolanta TAMOŠAITIENE் $2^{*}$ \\ ${ }^{1}$ Faculty of Engineering, Shahrekord University, Shahrekord, Iran \\ ${ }^{2}$ Faculty of Civil Engineering, Vilnius Gediminas Technical University, \\ Sauletekio al. 11, LT-10223 Vilnius, Lithuania
}

Received 17 February 2018; accepted 03 December 2018

\begin{abstract}
Construction projects are associated with a number of uncertainties due to their expanse, complex nature, uniqueness, and dynamic states. Risks in construction projects are, indeed, the events or uncertain situations that can have negative or positive consequences on the project objectives. Many of the risks inherent in construction projects affect each other. For example, the time risk in construction projects can affect the cost risk and vice versa. The intertwined relations between risk factors are ignored in the traditional construction risk assessment methods. To fulfill this gap, this paper proposes an integrated fuzzy DEMATEL-fuzzy ANP model to evaluate construction projects and their overall risks by considering intertwined relations among risk factors. Fuzzy DEMATEL is used to determine the interrelationships and interdependencies among risk factors. The network structure for implementing the fuzzy ANP method is extracted based on the results of fuzzy DEMATEL. The fuzzy ANP is applied to assess the relative importance of risk factors and alternatives and prioritize construction projects. The proposed integrated model is used to evaluate five construction projects based on risk factors in Isfahan, Iran. The results of applying the integrated model reveal that the time, cost and safety risks with the weight values of $0.056,0.038$, and 0.034 are the most important factors among construction risks, respectively. The results reveal that the proposed model can help managers to evaluate the overall risks of construction projects, and select the best project that has the lowest risk.
\end{abstract}

Keywords: construction projects, risk assessment, interrelations among risk factors, fuzzy DEMATEL, fuzzy analytic network process (ANP).

\section{Introduction}

Risk assessment in construction projects

Construction projects are defined as an unrepeatable effort and attempt with a high number of unique features, such as long period, complex processes, inappropriate environment, financial difficulties, capital, and dynamic organizational structure (Flanagan \& Norman, 1993). Such organizational and technological complexities bring about a lot of risks. The diversity of stakeholders' interests in construction projects aggravates the variability and complexity of risks. The placement of one's focus and concentration on what should be achieved in a construction project (for example, project objectives), the risk management process provides a perception of what might put the project objectives at risk and what needs to be done to ensure success (Tah \& Carr, 2002). Risk management is an important field in the construction industry, which has received the attention of researchers, project managers, shareholders, and etc. these days (Tamošaitienè, Turskis, \& Zavadskas, 2008; Tamošaitienè, Zavadskas \& Turskis, 2013; Iqbal, Choudhry, Holschemacher, Ali, \& Tamošaitienė, 2015). The origin of risks in construction projects is, in fact, the uncertainties in these projects. Known risks are those that have been identified and analyzed, and there is the potential for arrangement in providing a response to them; however, there is no potential for preventive management in case of unknown risks and the project team will provide a probable plan. Organizations have found that risk is a threat to the project success or an opportunity for effective and efficient project success. The risks that present a threat to a project may be accepted if they are in balance with risk-taking results (KarimiAzari, N. Mousavi, S. F. Mousavi,

${ }^{*}$ Corresponding author. E-mail: jolanta.tamosaitiene@vgtu.lt 
\& Hosseini, 2011). Winch (2002) argues that the implementation of quantitative risk management techniques is difficult and complex and, thereby, it requires accurate data. Unfortunately, such data are either difficult to obtain or are not available in the manufacturing industry. Moreover, the application of these data for illustrating the uncertainties is difficult. Therefore, it seems necessary to develop a risk analysis model for identifying and assessing the risks of construction projects that would solve the problem of the need for accurate data. The nature of construction projects involves the imposed uncertainties in which the risk analysis process is contingent upon the analysts' thinking. This prevents the use of many risk assessment methods.

There are several methods used in the literature review for risk assessment in construction projects. The probability and impact matrix is a common method for evaluating the risk of projects. El-Sayegh and Mansour (2015) assessed the risks in freeway construction projects in the United Arab Emirates. For this purpose, they used probability and impact matrices to evaluate the projects based on internal and external risk factors. Samantra, Datta, and Mahapatra (2017) introduced an integrated risk assessment methodology based on fuzzy theory to assess the risks of urban construction projects. The authors embarked on identifying and classifying the risks using used a hierarchical structure in their research. Then, they defined the risk rate as a function of the possibility and severity of the risk occurrence and, accordingly, assessed the risks of metro stations. In other research, Chau Ngoc et al. (2017) identified risk models in bridge and road construction projects in Vietnam, where they identified the risks existing in bridge and road construction projects through questionnaire and expert opinion. Then, they classified the identified risks into four categories of contractor risks, project risks, owner risks, and external risks. The authors identified the probability and severity of each identified risk for small, medium, and large scale in bridge and road construction projects. The results of their study may help decision-makers be aware of the probability and severity of the occurrence of risks and, thereby, develop appropriate strategies for eliminating or reducing the risks effects.

Application multi-attribute decision-making methods for risk management in construction projects can be seen in a large part of the literature review. For instance, Zavadskas, Turskis, and Tamošaitienè (2010) evaluated the risks of construction projects using TOPSIS-grey and COPRAS-G methods. Nieto-Morote and Ruz-Vila (2011) used fuzzy theory to assess the risk of construction projects by means of the fuzzy Analytic Hierarchy Process (AHP). In one of the recent studies, Taylan, Bafail, Abdulaal, and Kabli (2014) used five risk criteria, namely cost, time, safety, quality, and environmental sustainability risks for the assessment of construction projects where they evaluated 30 projects using fuzzy AHP and fuzzy TOPSIS. In another recent study, the tunneling project risks were initially identified and, then, they were evaluated and prioritized using a fuzzy inference system (YazdaniChamzini, 2014). T. Wang, S. Wang, Zhang, Huang, and Li
(2016) introduced a risk assessment framework based on an adapted AHP risk assessment model for submarine risk assessment in China and considered time risks to evaluate the risks emanating from external factors. Valipour, Yahaya, Noor, Antuchevičiene, and Tamošaitienè (2017) proposed a risk assessment framework based on the integrated SWARA and COPRAS method for the evaluation of excavation projects in Shiraz. Islam, Nepal, Skitmore, and Attarzadeh (2017) used Bayesian fuzzy networks to evaluate construction project risks. In their research, they initially investigated risk assessment methods in construction projects and arrived at the conclusion that the Bayesian fuzzy network can be considered as an effective tool for risk assessment. A hybrid MCDM technique based on the ANP method in $D$ numbers and an extended multi-attributive border approximation area comparison (MABAC) method in $D$ numbers is proposed for evaluating risk factors and prioritizing risk response strategies (Chatterjee, Zavadskas, Tamošaitiené, Adhikary, \& Kar, 2018). Ghasemi, Sari, Yousefi, Falsafi, and Tamošaitienè (2018) utilized and Bayesian network methodology for project portfolio risk identification and analysis by considering project risk interactions. According to the aforementioned studies, just Ghasemi et al. (2018) considered risk interactions by a Bayesian network methodology for project portfolio risk assessment. A hybrid model of DEMATEL and ANP as a powerful tool for identifying risk interactions and evaluating construction projects is proposed in this paper. In the next subsection, applications of DEMATEL and ANP models are reviewed in various fields.

\section{Application of fuzzy DEMATEL-fuzzy ANP models}

Various applications of fuzzy DEMATEL-fuzzy ANP models can be seen in the literature review. In this line of research, Tseng (2011) proposed an evaluation methodology based on the fuzzy DEMATEL-fuzzy ANP to evaluate environmental practice in knowledge management capability (EKMC) criteria to a case's firm. Ebrahimnejad, Mousavi, Tavakkoli-Moghaddam, Hashemi, and Vahdani (2012) proposed ANP-VIKOR model for construction project selection in a fuzzy environment by considering risk factors. Jeng and Tzeng (2012) designed a new clinical decision support system based on the fuzzy DEMATEL to examine the new technology acceptance. Büyüközkan and Çifçi (2012) proposed a fuzzy DEMATEL-fuzzy ANP-fuzzy TOPSIS for evaluating green suppliers in supply chain management. Chien, Wu, and Huang (2014) applied the DEMATEL technique for identifying and assessing critical risk factors for building information modeling projects. Zhou, Bai, and Sun (2014) utilized the ANP and DEMATEL model both together to obtain an effective safety assessment for hydropower-construction-projects. Ren and Sovacool (2014) utilized the fuzzy DEMATEL methodology to reveal cause-effect relationships among energy security criteria and prioritize energy security strategies. Tsai et al. (2015) proposed to use fuzzy DEMATEL to determine the environmental performance in printed circuit board (PCB) industry in Taiwan. Liou, Tamošaitienè, 
Zavadskas, and Tzeng (2016) presented new hybrid MADM Model based on the DEMATEL, ANP and COPRAS-G for improving and selecting suppliers in green supply chain management. The authors employed fuzzy DEMATEL to assess the direction and level of interaction between environmental performance criteria. Uygun and Dede (2016) proposed fuzzy DEMATEL-fuzzy ANP- fuzzy TOPSIS to measure the performance of alternative companies based on the criteria of green supply chain management. The authors employed the fuzzy DEMATEL-fuzzy ANP to determine the weight of green criteria in supply chain management. Özdemir and Tüysüz (2017) employed fuzzy DEMATEL-fuzzy ANP to determine the relationships between the perspectives and the strategies in a balanced scorecard model and also to prioritize the strategies in Turkish universities. Seker and Zavadskas (2017) applied fuzzy DEMATEL for analyzing occupational risks on construction sites. A hybrid model of ANP and an extended multi-attributive border approximation area comparison method in $D$ numbers are developed to assess the overall risks in construction projects and prioritize the risk response strategies (Chatterjee et al., 2018).

Previous studies did not consider the interrelationships among risk factors in the process of risk assessment of construction projects. In this paper, an integrated model of fuzzy DEMATEL and fuzzy ANP is proposed to identify the interdependencies of risk factors and the importance of risk factors. DEMATEL is a comprehensive method for constructing the causal relationships of structural models with respect to different complex factors. Furthermore, the fuzzy ANP technique helps us to determine the importance of risk factors by considering the interdependencies of risk factors determined by fuzzy DEMATEL. Although, application of fuzzy DEMATEL, fuzzy ANP, and the hybrid model of DEMATEL-ANP in fuzzy form are investigated in various fields, however, applying this hybrid model for evaluating and prioritizing construction projects by considering intertwined relations among risk factors is new. Table 1 briefly reviewed the recent application of fuzzy DEMATEL and fuzzy ANP models. The second column of this table states the subjects of the related study. The third, fourth, and fifth columns show the model applied in the study. The last column indicates whether the research used fuzzy concepts or not? According to Table 1, it can be concluded that the hybrid fuzzy DEMATELfuzzy ANP is applied in various fields. However, there is a research gap between current paper and prior studies in its application field. This paper addresses the new application of the hybrid fuzzy DEMATEL-fuzzy ANP model for construction project selection, which enables us to consider intertwined relations among risk factors. In this line of research, Ebrahimnejad et al. (2012) applied only fuzzy ANP for construction project selection based on the risk factors. Furthermore, Ghasemi et al. (2018) considered risk interactions by a Bayesian Network method for project portfolio risk assessment and other studies neglected risk

Table 1. Application of DEMATEL-ANP models

\begin{tabular}{|l|l|c|c|c|c|}
\hline \multicolumn{1}{|c|}{ Reference } & \multicolumn{1}{|c|}{ Subject } & DEMATEL & ANP & $\begin{array}{c}\text { Hybrid } \\
\text { DEMATEL-ANP }\end{array}$ & $\begin{array}{c}\text { Applying } \\
\text { fuzzy concept }\end{array}$ \\
\hline Tseng (2011) & $\begin{array}{l}\text { Evaluating firm environmental knowledge } \\
\text { management }\end{array}$ & & $\checkmark$ & $\checkmark$ \\
\hline $\begin{array}{l}\text { Büyüközkan and Çif̧i } \\
\text { (2012) }\end{array}$ & Supplier selection problem & & & $\checkmark$ & $\checkmark$ \\
\hline $\begin{array}{l}\text { Ebrahimnejad et al. } \\
\text { (2012) }\end{array}$ & Construction project selection & & $\checkmark$ & & $\checkmark$ \\
\hline Jeng and Tzeng (2012) & Designing a new clinical decision support system & $\checkmark$ & & & $\checkmark$ \\
\hline Chien et al. (2014) & $\begin{array}{l}\text { Risk assessment in building information } \\
\text { modeling projects }\end{array}$ & $\checkmark$ & & & \\
\hline Zhou et al. (2014) & Safety assessment in hydropower projects & & & $\checkmark$ & \\
\hline $\begin{array}{l}\text { Ren and Sovacool } \\
\text { (2014) }\end{array}$ & Energy security assessment & $\checkmark$ & & & $\checkmark$ \\
\hline Tsai et al. (2015) & $\begin{array}{l}\text { Evaluating environmental performance in PCB } \\
\text { industry }\end{array}$ & $\checkmark$ & & & $\checkmark$ \\
\hline $\begin{array}{l}\text { Uygun and Dede } \\
\text { (2016) }\end{array}$ & $\begin{array}{l}\text { Measuring the performance of green supply } \\
\text { chain management }\end{array}$ & & & $\checkmark$ & $\checkmark$ \\
\hline $\begin{array}{l}\text { Özdemir and Tüysüz } \\
\text { (2017) }\end{array}$ & Prioritizing strategies in educational Institutions & & & $\checkmark$ & $\checkmark$ \\
\hline $\begin{array}{l}\text { Seker and Zavadskas } \\
\text { (2017) }\end{array}$ & $\begin{array}{l}\text { Analyzing occupational risks on construction } \\
\text { sites }\end{array}$ & $\checkmark$ & & & $\checkmark$ \\
\hline Chatterjee et al. (2018) & Risk assessment in construction projects & & $\checkmark$ & & $\checkmark$ \\
\hline This paper & $\begin{array}{l}\text { Evaluating construction projects based on risk } \\
\text { factors }\end{array}$ & & & $\checkmark$ & $\checkmark$ \\
\hline
\end{tabular}


interactions when assessing construction risks. To sum up, to fulfill the research gap in its application point of view, this paper utilizes the hybrid fuzzy DEMATEL-fuzzy ANP for construction project selection with regard to the risk interactions.

The rest of this article is organized as follows. In the Section 1, the problem statement is presented. The proposed integrated method of fuzzy DEMATEL-fuzzy ANP is presented in full detail in Section 2. The case study, the risk factors and their sub-factors and the studied construction project alternatives are introduced in Section 3. The implementation of the proposed methodology for assessing 5 recreational, tourism, and commercial projects in the metropolitan city of Isfahan is elaborated in Section 4. Discussions and managerial and engineering implications are stated in Section 5. Finally, concluding remarks are reported in Conclusion.

\section{Problem statement}

Multi-criteria decision-making methods are the most widely used tools for solving the construction project evaluation problem. In these methods, a number of alternatives are evaluated based on a set of criteria. Since construction projects are in a complex and uncertain environment, the need to use the risk criteria to evaluate construction projects is recommended (Taylan et al., 2014). Therefore, multi-criteria decision-making methods have been used to evaluate construction projects by taking into account risk factors. In fact, many risk factors affect each other. For example, cost, time and quality risks affect each other. In other words, the risk associated with the cost of a construction project may increase the project time. Therefore, time risk is affected by the cost risk. The existing methods did not consider the interrelationship among risk factors when evaluating construction projects (Ghasemi et al., 2018). The aim of this paper is to propose an integrated model of fuzzy DEMATEL-fuzzy ANP to evaluate construction projects by considering intertwined relations among risk factors. Determining the dependencies of risk factors is a difficult task. Fortunately, the DEMATEL method is a powerful tool for determining the interrelations among risk factors. In other words, this technique by considering the interrelationship of criteria determines the degree of impact of criteria and their importance (Gabus \& Fontela, 1972). The most important characteristic of the DEMATEL method is its function to create relationships and structure among the factors. This technique provides the cause-and-effect relationships in an empirical structural model, and also makes it possible to identify the interdependencies between the factors and make them understandable.

In general, it is very difficult to estimate the opinion of experts with precise numbers, especially under uncertain situations, because the outcome of decisions is heavily dependent on the imprecise and vague mental judgments. Therefore, developing the fuzzy form of DEMATEL is highly recommended. The fuzzy DEMATEL technique uses fuzzy linguistic variables to facilitate decision making under uncertainty (Lin \& Wu, 2008).

Fuzzy DEMATEL is utilized to construct the network structure among risk factors. The network structure determined by fuzzy DEMATEL is employed for implementing fuzzy ANP. The ANP is an extended form of the analytic hierarchy process (AHP) which was first developed by Saaty (1996). AHP only considers the hierarchical relations among criteria and alternatives, while ANP considers all interrelationships among criteria and alternatives (Büyüközkan \& Çifçi, 2012). Furthermore, ANP can obtain the final weights of criteria and alternatives and prioritize them when there are interrelations among risk factors.

The questions that will be discussed in this study include:

1) How are interrelations among risk factors in construction projects?

2) What are the weights of risk factors by implementing the integrated fuzzy DEMATEL-fuzzy ANP model?

3) How is the priority of construction projects by applying the integrated fuzzy DEMATEL-fuzzy ANP model?

\section{Proposed methodology}

An integrated fuzzy DEMATEL-fuzzy ANP model is proposed in this paper for evaluating construction projects based on the intertwined relations among risk factors. Figure 1 shows the steps for implementing the proposed methodology. As this Figure shows, risk factors in construction projects are obtained from the literature review and finalized by experts' opinions in the first step. In the second step, after determining the risk factors, a questionnaire is designed for extracting the interrelationships among risk factors. In the third step, the fuzzy DEMATEL is applied to the gathered data and the relations and dependencies among risk factors are determined. The fuzzy DEMATEL has the following stages:

- Stage 1: Compute initial direct-relation fuzzy matrix;

- Stage 2: Defuzzify the initial direct-relation fuzzy matrix;

- Stage 3: Normalize the defuzzified initial direct-relation matrix;

- Stage 4: Compute the total relation matrix;

- Stage 5: Calculate the threshold value and determine the relationships among risk factors.

Based on the results of applying fuzzy DEMATEL, the network structure of the studied problem is obtained by considering the extracted relations among risk factors and construction project alternatives in the fourth step. In the fifth step, a questionnaire is designed based on the pairwise comparisons to obtain the local weights of risk factors and construction project alternative. In step sixth, fuzzy ANP is applied to the data of pairwise comparison questionnaire to obtain the final weights of risk factors and construction project alternatives. The fuzzy ANP has the following stages: 
Identifying risk factors in construction projects based on the literature review and experts' opinions

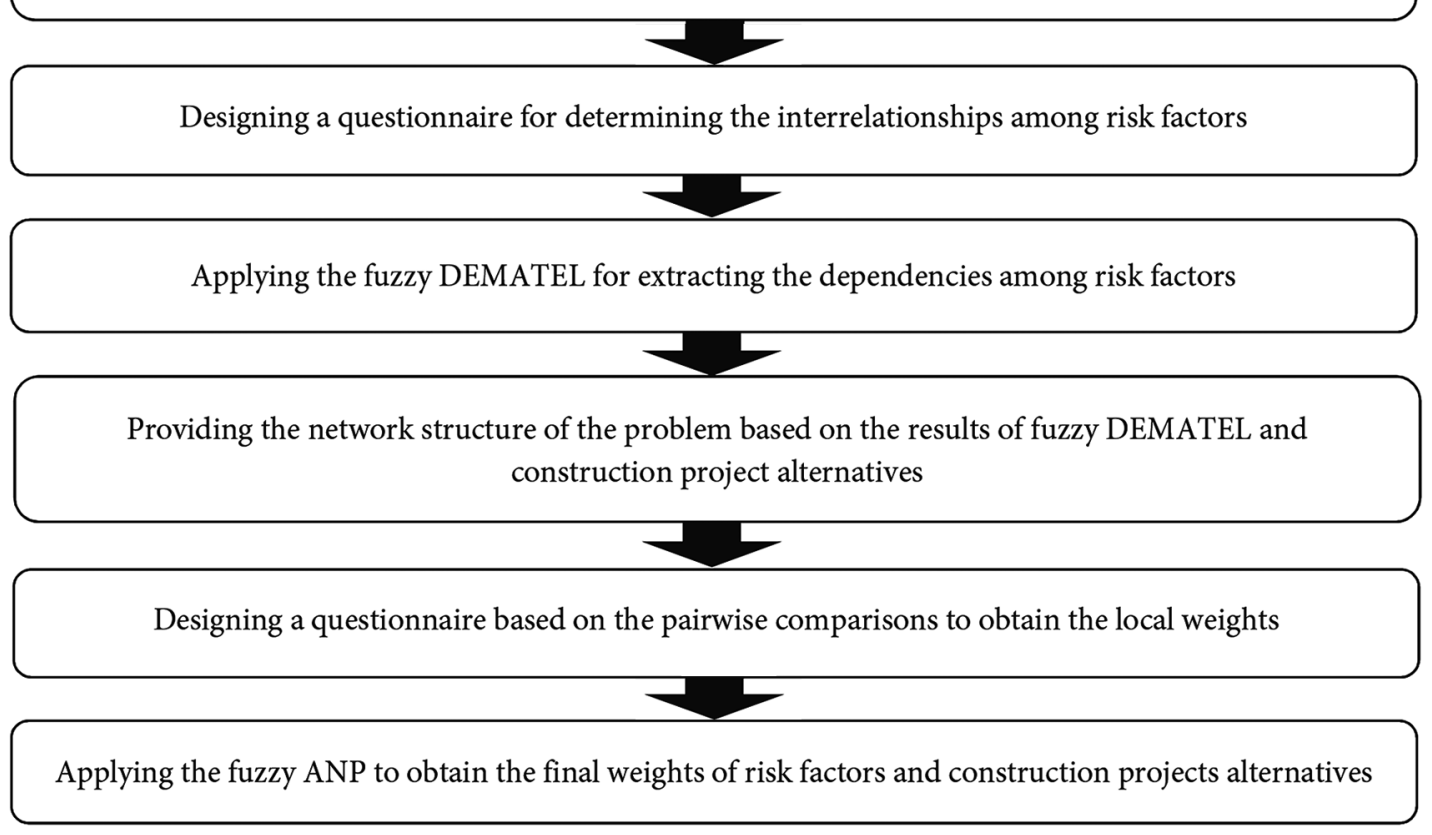

Figure 1. The proposed model

- Stage 1: Obtaining the fuzzy pairwise comparison matrices;

- Stage 2: Defuzzification of experts' opinions and aggregate their opinions;

- Stage 3: Calculation of local weights;

- Stage 4: Formation of the supermatrix;

- Stage 5: Determine the final weights of criteria, subcriteria, and alternatives.

Both fuzzy DEMATEL and fuzzy ANP questionnaires are presented in Appendix 1. The fuzzy DEMATEL and fuzzy ANP and their mathematical formulations are described in detail in this section.

\subsection{Fuzzy DEMATEL}

The procedure of implementing fuzzy DEMATEL is also completely based on the procedure in its certain state, with the exception that, in this case, fuzzy triangular numbers are applied and the relevant defuzzification computations and operations are performed ( $\mathrm{Lin} \& \mathrm{Wu}, 2008)$. The fuzzy DEMATEL stages are stated as follows.

\section{Stage 1: Compute initial direct-relation fuzzy matrix}

In this research, for the investigation of the interrelations among the factors, experts are requested to make the pairwise comparisons between the factors in terms of the influence rate of row factor $i$ on the column factor $j$. Therefore, the scale used in the certain mode is changed and the fuzzy linguistic scale is used in order to consider the existing ambiguities in the evaluations performed by experts. It is noteworthy that this linguistic scale has been stated in different studies via varying degrees of "influence" in the form of 5 linguistic terms, namely very high, high, low, very low, and no influence. The fuzzy triangular numbers corresponding to the current linguistic terms are based on the research of Wei and Yu (2007). These numbers can be observed in Table 2.

Due to the high capability of fuzzy numbers in simulating the decision-making process in human minds, the convertible linguistic variables into triangular fuzzy numbers have been used to convert qualitative responses of experts into quantitative values. Hence, the initial direct-relation fuzzy matrix $(\widetilde{Z})$ is formed after conducting the pairwise comparisons between criteria in terms of their influence in the form of linguistic expressions and their conversion into triangular fuzzy numbers.

\section{Stage 2: Defuzzify the initial direct-relation fuzzy matrix}

In order to obtain the interrelations between the criteria, the initial direct-relation fuzzy matrix must be defuzzified and converted into the crisp mode. Therefore, in this step, the CFCS method introduced by Opricovic and Tzeng (2003), which consists of five steps, will be used to defuzzify the initial direct-relation fuzzy matrix. Assume

Table 2. Linguistic terms and corresponding fuzzy triangular fuzzy numbers for influence between criteria

\begin{tabular}{|l|c|}
\hline \multicolumn{1}{|c|}{ Linguistic term } & Triangular fuzzy number \\
\hline Very High influence (NO) & $(0.75,1.0,1.0)$ \\
High influence (NO) & $(0.5,0.75,1)$ \\
Low influence (L) & $(0.25,0.5,0.75)$ \\
Very Low influence (VL) & $(0,0.25,0.5)$ \\
No influence (NO) & $(0,0,0.25)$ \\
\hline
\end{tabular}


that $\tilde{z}_{i j}^{k}=\left(l_{i j}^{k}, m_{i j}^{k}, k\right)$ is an element of the triangular initial direct-relation fuzzy matrix $(\tilde{Z})$, which is representative of the fuzzy evaluation obtained from the $k$ th expert about the influence of criterion $i$ on criterion $j$. The following five sub-steps ( $a, b, c, d$, and e) should be performed to defuzzify the initial direct-relation fuzzy matrix (Opricovic \& Tzeng, 2003; Tseng, 2011):

a) Calculate the normalized initial direct-relation matrix (matrix $\tilde{X}$ ).

In this step, the following relations are used to normalize the initial direct-relation fuzzy matrix.

$$
\begin{aligned}
& x l_{i j}^{k}=\left(l_{i j}^{k}-\min l_{i j}^{k}\right) / \Delta_{\min }^{\max } ; \\
& x m_{i j}^{k}=\left(m_{i j}^{k}-\min l_{i j}^{k}\right) / \Delta_{\min }^{\max } ; \\
& x r_{i j}^{k}=\left(r_{i j}^{k}-\min l_{i j}^{k}\right) / \Delta_{\min }^{\max },
\end{aligned}
$$

where $\Delta_{\min }^{\max }=\max r_{i j}^{k}-\min l_{i j}^{k}$;

b) Calculate left $(l s)$ and right $(r s)$ normalized values:

$$
\begin{aligned}
& x l s_{i j}^{k}=x m_{i j}^{k} /\left(1+x m_{i j}^{k}-x l_{i j}^{k}\right) ; \\
& x r s_{i j}^{k}=x r_{i j}^{k} /\left(1+x r_{i j}^{k}-x m_{i j}^{k}\right) ;
\end{aligned}
$$

c) Calculate total normalized crisp values:

$$
x_{i j}^{k}=\left[x l s_{i j}^{k}\left(1-x l s_{i j}^{k}\right)+x r s_{i j}^{k} x r s_{i j}^{k}\right] /\left[1-x l s_{i j}^{k}+x r s_{i j}^{k}\right] ;
$$

d) Calculate total crisp values:

$$
z_{i j}^{k}=\min l_{i j}^{k}+x_{i j}^{k} \Delta_{\min }^{\max } ;
$$

e) Aggregate the crisp values corresponding to the opinion of $p$ experts:

$$
Z_{i j}=\frac{1}{p}\left(z_{i j}^{1}+z_{i j}^{2}+\cdots+z_{i j}^{p}\right) .
$$

The element of $Z_{i j}$ represents the degree of influence that criterion $i$ has on criterion $j$. Therefore, matrix $Z$ is the defuzzified initial direct-relation matrix, which has resulted from the defuzzification of the comments made by $p$ experts.

\section{Stage 3: Normalize the defuzzified initial direct-relation} matrix

The defuzzified initial direct-relation matrix $Z$ can be converted into the normalized direct-relation matrix $(Y)$ by the following formula (Tseng, 2011):

$$
\begin{aligned}
& Y=s . Z ; \\
& s=\frac{1}{\max _{1 \leq i \leq n} \sum_{j=1}^{n} Z_{i j}} .
\end{aligned}
$$

Stage 4: Compute the total relation matrix

The total-relation matrix $T$ can be calculated through the following equation wherein $I$ denotes the identity matrix (Tzeng, Chiang, \& Li, 2007; Tseng, 2011):

$$
T=Y(I-Y)^{-1} .
$$

Stage 5: Calculate the threshold value and determine the relationships among risk factors

The threshold value should be calculated to determine the relationship-map among risk factors. This method can overlook the minor relationships between the factors and draw the network of dependable relationships. Only the relations between the factors are considered whose values in matrix $T$ are greater than the threshold value. In other words, if the element value of the $i$-th row and the $j$-th column exceeds the threshold value, this means that the $i$-th factor affects the $j$-th factor. In case, this element value is smaller than the threshold value, the $i$-th factor has a minimal impact on the $j$-th factor and this partial relationship can be ignored. To determine the threshold value, one can use the mean value of the elements of the total-relation matrix.

\subsection{Fuzzy ANP}

The analytic network process does not solely consider a mere hierarchical structure of the problem, but it models the problem using a feedback-based system. A feedback system can be represented by a network in which the nodes indicate components (Saaty, 2005). In the real world, many of the decisions contain ambiguous expressions made by humans. Linguistic estimates are suggested to be converted into fuzzy numbers in order to integrate a decision-makers experiences, beliefs, and ideas. ANP method makes use of a pairwise comparison matrix for rating and ranking preferences where the input data are crisp values. It is noteworthy that this matrix cannot be used in cases where the input data are uncertain. Leung and Cao (2000) argue that one of the reasons for the low accuracy of this method is that the experts are asked to assign a precise ratio to the pairwise comparison of phenomena based on his/her personal perception of the phenomena, while one's perception of a phenomenon is not expressible in the form of a crisp value, but a range of the values can better represent one's perception of the importance of a phenomenon in relation to another phenomenon than a crisp value. Therefore, fuzzy ANP can simulate the decision-making process in human minds better than the conventional ANP. Hence, in the phase of expert opinion collection, tangible linguistic terms in the fuzzy ANP pairwise comparison questionnaire have been used rather than the common crisp ratios in the conventional ANP. The fuzzy ANP has the following stages.

\section{Stage 1: Obtaining the fuzzy pairwise comparison matrices}

Pairwise comparisons are used in order to determine the importance of the criteria with respect to each other. To this end, experts' opinions are gathered in the form of the linguistic terms presented in Table 3 and are then converted to the corresponding fuzzy numbers. Thus, the conduct of the pairwise comparison matrix and the conversion of linguistic terms into the corresponding fuzzy 
Table 3. Linguistic terms and corresponding fuzzy triangular numbers

\begin{tabular}{|l|c|c|}
\hline \multicolumn{1}{|c|}{ Linguistic term } & $\begin{array}{c}\text { Fuzzy } \\
\text { triangular } \\
\text { number }\end{array}$ & $\begin{array}{c}\text { Fuzzy triangular } \\
\text { reciprocal } \\
\text { number }\end{array}$ \\
\hline Equally Important (EI) & $(1,1,1)$ & $(1,1,1)$ \\
Weekly Important (WI) & $(1,3,5)$ & $(1 / 5,1 / 3,1)$ \\
Strongly Important (SI) & $(3,5,7)$ & $(1 / 7,1 / 5,1 / 3)$ \\
Very Important (VI) & $(5,7,9)$ & $(1 / 9,1 / 7,1 / 5)$ \\
Absolutely Important (AI) & $(7,9,9)$ & $(1 / 9,1 / 9,1 / 7)$ \\
\hline
\end{tabular}

numbers lead to the generation of the fuzzy pairwise comparison matrix.

Stage 2: Defuzzification of experts' opinions and aggregate their opinions

The use of fuzzy ANP promotes the decision-making capability in reflecting the expert's perception of the importance of phenomena. The conversion of the pairwise comparison matrix from the fuzzy scale to the crisp scale is called the defuzzification of the pairwise comparison fuzzy matrix. After obtaining fuzzy pairwise comparison matrix by each expert' opinion, they are aggregated by arithmetic mean. Different methods have been proposed for the defuzzification of fuzzy pairwise comparison matrices. In this study, the aggregated fuzzy pairwise comparison matrices are defuzzified by the mentioned the CFCS method.

\section{Stage 3: Calculation of local weights}

Following the defuzzification of the aggregated pairwise comparison fuzzy matrix, the local weights of the criteria are obtained from the final defuzzified matrix via the following equation (Saaty, 2005). In fact, the weight of each criterion or sub-criterion is obtained by dividing the geometric mean of a row (row represents the criterion or sub-criterion) of the defuzzified pairwise comparison matrix by the sum of the geometric mean of the rows of that matrix:

$$
W_{i}=\frac{\left(\Pi_{j=1}^{n} a_{i j}\right)^{1 / n}}{\left.\sum_{i=1}^{n} \Pi_{j=1}^{n} a_{i j}\right)^{1 / n}}, \quad i, j=1,2, \ldots, n .
$$

\section{Stage 4: Formation of the supermatrix}

To perform the calculations pertaining to fuzzy ANP, the supermatrix must first be formed, which needs the utilization of four categories of local weights, as follows:

a) Local weights derived from the fuzzy pairwise comparison matrix of the main criteria relative to each other in relation to the objective.

b) Local weights derived from the fuzzy pairwise comparison matrix of the sub-criteria relative to each other in relation to the relevant criterion.

c) Local weights derived from the fuzzy pairwise comparison matrix of the sub-criteria of an effective main criterion in relation to each of the sub-criteria of a related influential criterion. Pairwise comparison matrices are constructed based on the mutual effects of the main criteria on each other, which is the output of the fuzzy DEMATEL method. Accordingly, the corresponding local weights are calculated.

d) Local weights derived from the pairwise comparison matrix of the alternatives in relation to each of the sub-criteria.

Stage 5: Determine the final weights of criteria, sub-criteria, and alternatives

If the extracted supermatrix at the previous stage covers the whole network, one can calculate the final weights of criteria, sub-criteria, and alternatives. To this end, the supermatrix should be normalized at first. The element pertaining to the $i$-th row and the $j$-th column of the normalized supermatrix is obtained from dividing the element pertaining to the $i$-th row and the $j$-th column of the supermatrix by the sum of the $j$-th elements of the supermatrix. According to Eqn (13), if we calculate the normalized supermatrix to the power of an adequately large odd number, the limited supermatrix will be obtained (Saaty, 2005):

$$
\operatorname{Lim}_{k \rightarrow \infty}\left(W_{n}\right)^{2 k+1},
$$

where $W_{n}$ represents the normalized supermatrix and $k$ is a desirable and large number, and the ability to bring the supermatrix to the power of a value allows the convergence and, consequently, the stability of the weights. The numbers of each row of the limited supermatrix converge to a number that indicates the final weight of the corresponding row (the final weight of the criterion, subcriterion, or alternative).

\section{Case study}

In this research, the integrated fuzzy DEMATEL-fuzzy ANP model is used to evaluate and prioritize five recreational, tourism, and commercial projects in the metropolitan city of Isfahan. Here, only the investment projects in Isfahan that is under construction or on the verge of operation have been considered. These projects are very diverse and only the projects with recreational and tourism applications have been included. The projects that make up the decision-making alternatives in this study include Sepahan Recreational and Commercial Complex $\left(A_{1}\right)$, Recreational and Commercial Complex of Negin Chargagh $\left(A_{2}\right)$, Recreational, Tourism, and Commercial Complex of Fadak Center $\left(A_{3}\right)$, Recreational, Commercial, and Administrative Complex of Anoushirvan $\left(A_{4}\right)$, and Recreational, Servicing, and Commercial Complex of Goldasteh Garden $\left(A_{5}\right)$. For the evaluation of these projects, risk factors are initially identified through the related literature review and experts' opinions in the field of construction. In one of the recent studies, Taylan et al. (2014) used five risk criteria, namely cost, time, safety, quality, and environmental sustainability risks for the assessment 
and selection of construction projects by using fuzzy AHP and fuzzy TOPSIS. The authors did not consider any subcriteria for each of the major risk criteria. In the present paper, these criteria are used to evaluate construction projects, with the difference that some sub-criteria have been considered for each of these criteria. For example, the subcriterion "weakness in construction schedule" $\left(C_{11}\right)$ and the sub-criterion "delay in supply of materials" $\left(C_{12}\right)$ have been considered in time risk $\left(C_{1}\right)$. In addition to the five main risk criteria presented by Taylan et al. (2014), human resources risk has been considered as another major risk factor in this research. In total, the risk criteria and subcriteria in the area of construction have been extracted from the research conducted by Taylan et al. (2014) and Yazdani-Chamzini (2014), and via expert opinions, as presented in Table 4.

For the implementation of the proposed method, it is necessary to first determine the interrelationship and mutual effects among the risk factors through fuzzy DEMATEL method. For this purpose, a questionnaire pertaining

Table 4. Identified risks in this research

\begin{tabular}{|c|c|c|}
\hline No. & $\begin{array}{l}\text { Risk factors } \\
\text { (main criteria) }\end{array}$ & Sub-criteria \\
\hline \multirow[t]{2}{*}{1} & \multirow{2}{*}{ Time risk $\left(C_{1}\right)$} & $\begin{array}{l}\text { Weakness in construction } \\
\text { schedule }\left(C_{11}\right)\end{array}$ \\
\hline & & Delay in supply of materials $\left(C_{12}\right)$ \\
\hline \multirow{5}{*}{2} & \multirow{5}{*}{ Cost risk $\left(C_{2}\right)$} & High price of tender $\left(C_{21}\right)$ \\
\hline & & Increase in materials prices $\left(C_{22}\right)$ \\
\hline & & Increase in labor cost $\left(C_{23}\right)$ \\
\hline & & $\begin{array}{l}\text { Delay in payment of costs } \\
\text { according to contract }\left(C_{24}\right)\end{array}$ \\
\hline & & Financial difficulties $\left(C_{25}\right)$ \\
\hline \multirow{4}{*}{3} & \multirow{4}{*}{ Quality risk $\left(C_{3}\right)$} & $\begin{array}{l}\text { Inappropriate selection of } \\
\text { equipment and devices }\left(C_{31}\right)\end{array}$ \\
\hline & & $\begin{array}{l}\text { Inappropriate selection of } \\
\text { materials }\left(C_{32}\right)\end{array}$ \\
\hline & & Machine failure $\left(C_{33}\right)$ \\
\hline & & Low quality of work $\left(C_{34}\right)$ \\
\hline \multirow{3}{*}{4} & \multirow{3}{*}{ Safety risk $\left(C_{4}\right)$} & Collapse of construction $\left(C_{41}\right)$ \\
\hline & & Staff safety $\left(C_{42}\right)$ \\
\hline & & $\begin{array}{l}\text { Unexpected events such as fire } \\
\text { during work }\left(C_{43}\right)\end{array}$ \\
\hline \multirow{4}{*}{5} & \multirow{4}{*}{$\begin{array}{l}\text { Environmental } \\
\text { sustainability } \\
\text { risk }\left(C_{5}\right)\end{array}$} & $\begin{array}{l}\text { Disruption to residents near the } \\
\text { construction site }\left(C_{51}\right)\end{array}$ \\
\hline & & Physical damage to workers $\left(C_{52}\right)$ \\
\hline & & Environmental constraints $\left(C_{53}\right)$ \\
\hline & & Noise $\left(C_{54}\right)$ \\
\hline \multirow{4}{*}{6} & \multirow{4}{*}{$\begin{array}{l}\text { Human } \\
\text { resources risk } \\
\left(C_{6}\right)\end{array}$} & Management inability $\left(C_{61}\right)$ \\
\hline & & $\begin{array}{l}\text { Lack of experienced professional } \\
\text { consultants }\left(C_{62}\right)\end{array}$ \\
\hline & & Exchange of key personnel $\left(C_{63}\right)$ \\
\hline & & Workers' strike $\left(C_{64}\right)$ \\
\hline
\end{tabular}

to the fuzzy DEMATEL method has been designed. After the collection of experts' opinions, the interrelationship and mutual effects between the risk criteria are clarified in the form of a fuzzy DEMATEL questionnaire and the implementation of the fuzzy DEMATEL method. Based on the way the risk criteria are interrelated and affect each other, a network structure is created among the criteria and alternatives. Finally, based on the created network structure, a questionnaire pertaining to fuzzy ANP is designed in which expert opinions about the importance of risk criteria relative to each other are gathered in the form of pairwise comparisons. The fuzzy DEMATEL and fuzzy ANP questionnaires are attached in Appendix 1.

According to Liang et al. (2016), the sample size between three and nine samples is adequate for data collection and analysis by MCDM methods like DEMATEL, AHP, ANP and etc. In this paper, all experts who are able to compare and evaluate the risk factors and construction project alternatives are selected to fulfill the questionnaires. Therefore, 10 experts were selected to be interviewed and completed the fuzzy DEMATEL and fuzzy ANP questionnaires. All experts have more than 5 years of management experience in the field of construction. Seven experts out of ten ones are working in the construction department of the municipality of Isfahan and have been engaged directly and indirectly in the studied construction projects. The remaining experts are one consultant and two professors in civil Engineering and industrial Engineering which have sufficiently experienced in the project management field.

\section{Results}

\subsection{Fuzzy DEMATEL}

The results of applying fuzzy DEMATEL-fuzzy ANP are reported in this section. For doing so, the defuzzification process presented in Eqns (1)-(8), the fuzzy DEMATEL introduced in Eqns (9)-(11), and the fuzzy ANP method are coded in SPLUS software. These codes are attached in Appendix 2. The code of defuzzification process is separately utilized to defuzzify a fuzzy matrix. The fuzzy DEMATEL code is used to perform the calculation of fuzzy DEMATEL. The fuzzy ANP code is employed to obtain the limited supermatrix. Furthermore, EXCEL software is used for the preparation of data of pairwise comparison matrices and converting them to fuzzy triangular numbers, obtaining local weights by formulation (12) and obtaining un-weighted and weighted super-matrices in fuzzy ANP.

As it was mentioned earlier, in the fuzzy DEMATEL method, the relationships between risk criteria are investigated. In this method, the influence of the major criteria on each other should be determined with the help of experts' opinions. For example, Table 5 shows how major risk factors affect each other based on the opinion of the first expert. The linguistic terms reported in Table 5 are converted to corresponding triangular fuzzy numbers using Table 2. The fuzzy numbers corresponding to linguistic terms have been reported in Table 5 . 
Table 5. The direct influence between the criteria based on the first expert's opinions

\begin{tabular}{|c|c|c|c|c|c|c|}
\hline & $C_{1}$ & $C_{2}$ & $C_{3}$ & $C_{4}$ & $C_{5}$ & $C_{6}$ \\
\hline$C_{1}$ & $\begin{array}{c}\mathrm{NO} \\
(0,0,0.25)\end{array}$ & $\begin{array}{c}\mathrm{VH} \\
(0.75,1.0,1.0)\end{array}$ & $\begin{array}{c}\mathrm{H} \\
(0.5,0.75,1)\end{array}$ & $\begin{array}{c}\mathrm{L} \\
(0.25,0.5,0.75)\end{array}$ & $\begin{array}{c}\mathrm{VL} \\
(0,0.25,0.5)\end{array}$ & $\begin{array}{c}\mathrm{VL} \\
(0,0.25,0.5)\end{array}$ \\
\hline$C_{2}$ & $\begin{array}{c}\mathrm{VH} \\
(0.75,1.0,1.0)\end{array}$ & $\begin{array}{c}\mathrm{NO} \\
(0,0,0.25)\end{array}$ & $\begin{array}{c}\mathrm{VH} \\
(0.75,1.0,1.0)\end{array}$ & $\begin{array}{c}\mathrm{H} \\
(0.5,0.75,1)\end{array}$ & $\begin{array}{c}\mathrm{NO} \\
(0,0,0.25)\end{array}$ & $\begin{array}{c}\mathrm{NO} \\
(0,0,0.25)\end{array}$ \\
\hline$C_{3}$ & $\begin{array}{c}\mathrm{L} \\
(0.25,0.5,0.75)\end{array}$ & $\begin{array}{c}\mathrm{VL} \\
(0,0.25,0.5)\end{array}$ & $\begin{array}{c}\text { NO } \\
(0,0,0.25)\end{array}$ & $\begin{array}{c}\mathrm{H} \\
(0.5,0.75,1)\end{array}$ & $\begin{array}{c}\mathrm{NO} \\
(0,0,0.25)\end{array}$ & $\begin{array}{c}\mathrm{VL} \\
(0,0.25,0.5)\end{array}$ \\
\hline$C_{4}$ & $\begin{array}{c}\mathrm{VL} \\
(0,0.25,0.5)\end{array}$ & $\begin{array}{c}\text { NO } \\
(0,0,0.25)\end{array}$ & $\begin{array}{c}\mathrm{H} \\
(0.5,0.75,1)\end{array}$ & $\begin{array}{c}\text { NO } \\
(0,0,0.25)\end{array}$ & $\begin{array}{c}\mathrm{NO} \\
(0,0,0.25)\end{array}$ & $\begin{array}{c}\mathrm{L} \\
(0.25,0.5,0.75)\end{array}$ \\
\hline$C_{5}$ & $\begin{array}{c}\mathrm{L} \\
(0.25,0.5,0.75)\end{array}$ & $\begin{array}{c}\mathrm{H} \\
(0.5,0.75,1)\end{array}$ & $\begin{array}{c}\mathrm{H} \\
(0.5,0.75,1)\end{array}$ & $\begin{array}{c}\mathrm{H} \\
(0.5,0.75,1)\end{array}$ & $\begin{array}{c}\mathrm{NO} \\
(0,0,0.25)\end{array}$ & $\begin{array}{c}\mathrm{VL} \\
(0,0.25,0.5)\end{array}$ \\
\hline$C_{6}$ & $\begin{array}{c}\mathrm{H} \\
(0.5,0.75,1)\end{array}$ & $\begin{array}{c}\mathrm{H} \\
(0.5,0.75,1)\end{array}$ & $\begin{array}{c}\mathrm{L} \\
(0.25,0.5,0.75)\end{array}$ & $\begin{array}{c}\mathrm{L} \\
(0.25,0.5,0.75)\end{array}$ & $\begin{array}{c}\mathrm{L} \\
(0.25,0.5,0.75)\end{array}$ & $\begin{array}{c}\mathrm{NO} \\
(0,0,0.25)\end{array}$ \\
\hline
\end{tabular}

The direct-relation fuzzy matrix presented in Table 5 are defuzzified by using Eqns (1)-(7) of the fuzzy DEMATEL method. For this purpose, normalized values, left (ls) and right (rs) normalized values, final normalized crisp values, and crisp values are computed. For example, the initial direct-relation defuzzified matrix derived from the first expert's opinions is reported in Table 6. Similarly, it is possible to obtain the initial direct-relation defuzzified matrix for all the experts. These matrices are aggregated using Eqn (8), and the aggregated initial direct-relation defuzzified matrix $(Z)$ is based on the opinion of 10 experts is reported in Table 7.

Table 6. The initial direct-relation defuzzified matrix based on the first expert's opinions

\begin{tabular}{|c|c|c|c|c|c|c|}
\hline & $C_{1}$ & $C_{2}$ & $C_{3}$ & $C_{4}$ & $C_{5}$ & $C_{6}$ \\
\hline$C_{1}$ & 0.033 & 0.967 & 0.733 & 0.500 & 0.267 & 0.267 \\
\hline$C_{2}$ & 0.967 & 0.033 & 0.733 & 0.733 & 0.033 & 0.033 \\
\hline$C_{3}$ & 0.500 & 0.267 & 0.033 & 0.733 & 0.033 & 0.267 \\
\hline$C_{4}$ & 0.267 & 0.033 & 0.733 & 0.033 & 0.033 & 0.500 \\
\hline$C_{5}$ & 0.500 & 0.733 & 0.733 & 0.733 & 0.033 & 0.267 \\
\hline$C_{6}$ & 0.733 & 0.733 & 0.500 & 0.500 & 0.500 & 0.033 \\
\hline
\end{tabular}

Table 7. The initial direct-relation defuzzified matrix $(Z)$ based on the opinions of ten experts

\begin{tabular}{|c|c|c|c|c|c|c|}
\hline & $C_{1}$ & $C_{2}$ & $C_{3}$ & $C_{4}$ & $C_{5}$ & $C_{6}$ \\
\hline$C_{1}$ & 0.033 & 0.616 & 0.583 & 0.444 & 0.132 & 0.137 \\
\hline$C_{2}$ & 0.391 & 0.033 & 0.279 & 0.397 & 0.366 & 0.121 \\
\hline$C_{3}$ & 0.302 & 0.302 & 0.033 & 0.679 & 0.100 & 0.124 \\
\hline$C_{4}$ & 0.200 & 0.366 & 0.062 & 0.033 & 0.395 & 0.106 \\
\hline$C_{5}$ & 0.220 & 0.142 & 0.540 & 0.540 & 0.033 & 0.267 \\
\hline$C_{6}$ & 0.540 & 0.215 & 0.106 & 0.679 & 0.200 & 0.033 \\
\hline
\end{tabular}

At the end, the total relation matrix $(T)$ is computed by applying Eqns (9) to (11) to matrix $Z$. This matrix has been presented in Table 8. As it was mentioned previously, the threshold value should be calculated to determine the interrelationships between risk factors. The mean value of the elements of the total relation matrix, which is equal to 0.224 , has been used as the threshold value.

If the value of the element pertaining to the $i$-th row and the $j$-th column is greater than 0.224 , then the $i$-th factor will affect the $j$-th factor. On the other hand, if this element is smaller than 0.224 , the $i$-th factor will have a minimal impact on the $j$-th factor, and this slight relationship can be ignored. For example, from the results presented in Table 8 , it can be concluded that factor $C_{1}$ affects factors $C_{2}, C_{3}$, and $C_{4}$. Based on the results presented in Table 8, the network structure presented in Figure 2 defines the relations among the risk factors, alternatives and the goal.

\subsection{Fuzzy ANP results}

After collecting the experts' opinions in the form of the linguistic items presented in Table 3, the fuzzy pairwise comparison matrix has been obtained for the opinions of each individual expert. Then, they are aggregated by arithmetic mean. For example, following the creation of the fuzzy pairwise comparison matrix about the main

Table 8. Total-relation matrix

\begin{tabular}{|l|l|l|l|l|l|l|}
\hline & $C_{1}$ & $C_{2}$ & $C_{3}$ & $C_{4}$ & $C_{5}$ & $C_{6}$ \\
\hline$C_{1}$ & 0.170 & $\mathbf{0 . 3 7 2}$ & $\mathbf{0 . 3 3 7}$ & $\mathbf{0 . 3 9 4}$ & 0.184 & 0.123 \\
\cline { 2 - 7 }$C_{2}$ & $\mathbf{0 . 2 5 7}$ & 0.162 & $\mathbf{0 . 2 3 1}$ & $\mathbf{0 . 3 4 1}$ & $\mathbf{0 . 2 3 3}$ & 0.111 \\
\cline { 2 - 7 }$C_{3}$ & 0.221 & $\mathbf{0 . 2 4 4}$ & 0.127 & $\mathbf{0 . 4 0 6}$ & 0.150 & 0.103 \\
\cline { 2 - 7 }$C_{4}$ & 0.168 & $\mathbf{0 . 2 2 7}$ & 0.132 & 0.171 & 0.219 & 0.091 \\
\cline { 2 - 7 }$C_{5}$ & 0.215 & 0.207 & $\mathbf{0 . 3 0 5}$ & $\mathbf{0 . 4 0 3}$ & 0.131 & 0.160 \\
\cline { 2 - 7 }$C_{6}$ & $\mathbf{0 . 3 1 7}$ & $\mathbf{0 . 2 4 5}$ & 0.183 & $\mathbf{0 . 4 4 0}$ & 0.197 & 0.083 \\
\hline
\end{tabular}




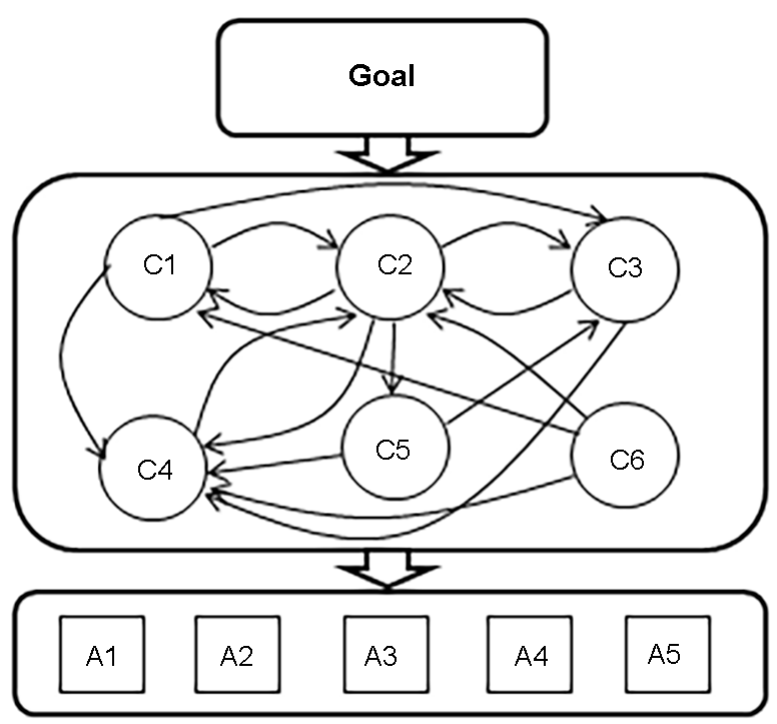

Figure 2. The proposed network structure

criteria based on ten experts' opinions, it will be defuzzified according to Eqns (1)-(7). The aggregated defuzzified pairwise comparison matrix of the main risk factors is reported in Table 9. Using Eqn (12), the local weights are extracted from this matrix. The aggregated defuzzified decision matrix and the local weights of the main risk factors are reported in the last column of Table 9.

Table 9. The aggregated defuzzified decision matrix of main criteria and local weights

\begin{tabular}{|c|c|c|c|c|c|c|c|}
\hline & $C_{1}$ & $C_{2}$ & $C_{3}$ & $C_{4}$ & $C_{5}$ & $C_{6}$ & $\begin{array}{c}\text { Local } \\
\text { weight }\end{array}$ \\
\hline$C_{1}$ & 1.000 & 5.174 & 3.513 & 3.303 & 1.656 & 2.804 & 0.343 \\
\hline$C_{2}$ & 0.193 & 1.000 & 2.913 & 1.248 & 6.899 & 5.606 & 0.233 \\
\hline$C_{3}$ & 0.283 & 0.345 & 1.000 & 0.391 & 4.517 & 0.601 & 0.092 \\
\hline$C_{4}$ & 0.304 & 0.798 & 2.552 & 1.000 & 2.834 & 7.729 & 0.208 \\
\hline$C_{5}$ & 0.602 & 0.144 & 0.223 & 0.352 & 1.000 & 1.887 & 0.065 \\
\hline$C_{6}$ & 0.356 & 0.178 & 1.661 & 0.128 & 0.530 & 1.000 & 0.059 \\
\hline
\end{tabular}

According to the stage 4 of fuzzy ANP method, for creating the initial supermatrix, the following four categories of local weights should be used: Local weights derived from the fuzzy pairwise comparison matrix of the main criteria in relation to the objective, local weights derived from the fuzzy pairwise comparison matrix of the subcriteria in relation to the respected main criterion, local weights derived from the fuzzy pairwise comparison matrix of the sub-criteria of an effective main criterion in relation to each of the sub-criteria of a related influential criterion, and the local weights of the alternatives in relation to the sub-criteria. In Table 9, the local weights extracted from the pairwise comparison matrix of the main criteria in relation to the goal have been reported. Similarly, other local weights can be obtained and used to prepare initial supermatrix. The initial supermatrix has been reported in
Table 10. After the creation of the initial supermatrix, the weighed supermatrix is obtained. For the creation of the weighed supermatrix, each element of the initial supermatrix is divided by the sum of the corresponding column elements.

At the end, the weighted supermatrix should be brought to the power of $2 k+1$ where $k$ is a large number (in this research, it equals 50) to compute the limited supermatrix (Table 11). In the limited supermatrix, the elements of each row converge to a number that indicates the final weight of the corresponding row. Accordingly, the final weights of the main criteria, sub-criteria, and alternatives can be extracted from limited supermatrix. The final weights of risk factors can be obtained from limited supermatrix. To validate the results provided by the proposed fuzzy DEMATEL-fuzzy ANP, they are compared with those obtained by fuzzy AHP in Taylan et al. (2014) research. Taylan et al. (2014) obtained fuzzy weights for five risk factors by fuzzy AHP and utilized them to prioritize 30 construction projects. These weights are defuzzified based on the centre of area method and reported in the fourth column of Table 12. The final weights of risk factors obtained by both fuzzy DEMATEL-fuzzy ANP and fuzzy AHP methods are reported in Table 12. According to the results of Table 12, time and cost risk factors are determined as the most critical factors according to both methods. The safety and quality risks have the third and fourth priorities by considering fuzzy DEMATEL-fuzzy ANP, respectively, while they achieve the fourth and third ranks according to the fuzzy AHP method. Furthermore, environmental sustainability risk gained the fifth priority among risk factors by applying both methods. Based on the aforementioned discussions, it can be concluded that the results of fuzzy DEMATEL-fuzzy ANP are validated by fuzzy AHP results used in Taylan et al. (2014).

The final weights of the alternatives are used to prioritize the construction projects. As the results are shown in Table 11, the final weights of the first, second, third, fourth, and fifth alternatives equal $0.037,0.038,0.028,0.034$, and 0.026 , respectively. Accordingly, $A_{2}$ is the highest risk category project and other alternatives are prioritized as $A_{2} \succ A_{1} \succ A_{4} \succ A_{3} \succ A_{5}$.

\section{Discussion and managerial implications}

The results of fuzzy DEMATEL show several relations among risk factors. The first row of Table 8 reveals that the time risk affects the cost, quality and safety factors in construction projects. The results of this table show that the cost risk influences the time, quality and safety risks. The quality risk has an influence on cost and safety risk factors. The safety risk just affects the cost risk. The environmental sustainability influences the quality and safety and the human resources risk affects the time, cost and safety factors. According to the fifth column of Table 8, it can be concluded that safety factor is the most effective risk factor, and it is determined as the highest effect factor, since it is affected by the time, cost, quality, environmen- 
Table 10. Initial supermatrix

\begin{tabular}{|c|c|c|c|c|c|c|c|c|c|c|c|c|c|c|c|c|c|}
\hline & $C_{1}$ & $C_{2}$ & $C_{3}$ & $C_{4}$ & $C_{5}$ & $C_{6}$ & $C_{11}$ & $C_{12}$ & $C_{21}$ & $C_{22}$ & $C_{23}$ & $C_{24}$ & $C_{25}$ & $C_{31}$ & $C_{32}$ & $C_{33}$ & $C_{34}$ \\
\hline$C_{1}$ & 0 & 0 & 0 & 0 & 0 & 0 & 0 & 0 & 0 & 0 & 0 & 0 & 0 & 0 & 0 & 0 & 0 \\
\hline$C_{2}$ & 0 & 0 & 0 & 0 & 0 & 0 & 0 & 0 & 0 & 0 & 0 & 0 & 0 & 0 & 0 & 0 & 0 \\
\hline$C_{3}$ & 0 & 0 & 0 & 0 & 0 & 0 & 0 & 0 & 0 & 0 & 0 & 0 & 0 & 0 & 0 & 0 & 0 \\
\hline$C_{4}$ & 0 & 0 & 0 & 0 & 0 & 0 & 0 & 0 & 0 & 0 & 0 & 0 & 0 & 0 & 0 & 0 & 0 \\
\hline$C_{5}$ & 0 & 0 & 0 & 0 & 0 & 0 & 0 & 0 & 0 & 0 & 0 & 0 & 0 & 0 & 0 & 0 & 0 \\
\hline$C_{6}$ & 0 & 0 & 0 & 0 & 0 & 0 & 0 & 0 & 0 & 0 & 0 & 0 & 0 & 0 & 0 & 0 & 0 \\
\hline$C_{11}$ & 0.829 & 0 & 0 & 0 & 0 & 0 & 0 & 0 & 0.446 & 0.489 & 0.565 & 0.549 & 0.534 & 0 & 0 & 0 & 0 \\
\hline$C_{12}$ & 0.171 & 0 & 0 & 0 & 0 & 0 & 0 & 0 & 0.554 & 0.511 & 0.435 & 0.451 & 0.466 & 0 & 0 & 0 & 0 \\
\hline$C_{21}$ & 0 & 0.371 & 0 & 0 & 0 & 0 & 0.147 & 0.171 & 0 & 0 & 0 & 0 & 0 & 0.268 & 0.275 & 0.250 & 0.228 \\
\hline$C_{22}$ & 0 & 0.169 & 0 & 0 & 0 & 0 & 0.217 & 0.189 & 0 & 0 & 0 & 0 & 0 & 0.218 & 0.218 & 0.217 & 0.177 \\
\hline$C_{23}$ & 0 & 0.088 & 0 & 0 & 0 & 0 & 0.227 & 0.227 & 0 & 0 & 0 & 0 & 0 & 0.103 & 0.126 & 0.160 & 0.198 \\
\hline$C_{24}$ & 0 & 0.326 & 0 & 0 & 0 & 0 & 0.208 & 0.206 & 0 & 0 & 0 & 0 & 0 & 0.200 & 0.174 & 0.196 & 0.175 \\
\hline$C_{25}$ & 0 & 0.046 & 0 & 0 & 0 & 0 & 0.201 & 0.206 & 0 & 0 & 0 & 0 & 0 & 0.211 & 0.207 & 0.178 & 0.222 \\
\hline$C_{31}$ & 0 & 0 & 0.231 & 0 & 0 & 0 & 0.190 & 0.255 & 0.266 & 0.265 & 0.213 & 0.112 & 0.315 & 0 & 0 & 0 & 0 \\
\hline$C_{32}$ & 0 & 0 & 0.126 & 0 & 0 & 0 & 0.342 & 0.258 & 0.325 & 0.348 & 0.134 & 0.259 & 0.298 & 0 & 0 & 0 & 0 \\
\hline$C_{33}$ & 0 & 0 & 0.569 & 0 & 0 & 0 & 0.182 & 0.238 & 0.150 & 0.189 & 0.358 & 0.231 & 0.146 & 0 & 0 & 0 & 0 \\
\hline$C_{34}$ & 0 & 0 & 0.074 & 0 & 0 & 0 & 0.286 & 0.249 & 0.259 & 0.198 & 0.295 & 0.398 & 0.241 & 0 & 0 & 0 & 0 \\
\hline$C_{41}$ & 0 & 0 & 0 & 0.626 & 0 & 0 & 0.340 & 0.384 & 0.394 & 0.334 & 0.357 & 0.381 & 0.291 & 0.283 & 0.341 & 0.344 & 0.367 \\
\hline$C_{42}$ & 0 & 0 & 0 & 0.274 & 0 & 0 & 0.277 & 0.242 & 0.273 & 0.331 & 0.305 & 0.327 & 0.348 & 0.311 & 0.257 & 0.318 & 0.288 \\
\hline$C_{43}$ & 0 & 0 & 0 & 0.100 & 0 & 0 & 0.383 & 0.374 & 0.333 & 0.335 & 0.337 & 0.292 & 0.362 & 0.406 & 0.401 & 0.338 & 0.345 \\
\hline$C_{51}$ & 0 & 0 & 0 & 0 & 0.283 & 0 & 0 & 0 & 0.167 & 0.263 & 0.283 & 0.265 & 0.187 & 0 & 0 & 0 & 0 \\
\hline$C_{52}$ & 0 & 0 & 0 & 0 & 0.186 & 0 & 0 & 0 & 0.149 & 0.166 & 0.109 & 0.113 & 0.208 & 0 & 0 & 0 & 0 \\
\hline$C_{53}$ & 0 & 0 & 0 & 0 & 0.417 & 0 & 0 & 0 & 0.419 & 0.266 & 0.378 & 0.427 & 0.407 & 0 & 0 & 0 & 0 \\
\hline$C_{54}$ & 0 & 0 & 0 & 0 & 0.114 & 0 & 0 & 0 & 0.264 & 0.305 & 0.230 & 0.195 & 0.198 & 0 & 0 & 0 & 0 \\
\hline$C_{61}$ & 0 & 0 & 0 & 0 & 0 & 0.351 & 0 & 0 & 0 & 0 & 0 & 0 & 0 & 0 & 0 & 0 & 0 \\
\hline$C_{62}$ & 0 & 0 & 0 & 0 & 0 & 0.152 & 0 & 0 & 0 & 0 & 0 & 0 & 0 & 0 & 0 & 0 & 0 \\
\hline$C_{63}$ & 0 & 0 & 0 & 0 & 0 & 0.426 & 0 & 0 & 0 & 0 & 0 & 0 & 0 & 0 & 0 & 0 & 0 \\
\hline$C_{64}$ & 0 & 0 & 0 & 0 & 0 & 0.070 & 0 & 0 & 0 & 0 & 0 & 0 & 0 & 0 & 0 & 0 & 0 \\
\hline$A_{1}$ & 0 & 0 & 0 & 0 & 0 & 0 & 0.231 & 0.188 & 0.210 & 0.257 & 0.260 & 0.249 & 0.217 & 0.189 & 0.228 & 0.199 & 0.228 \\
\hline$A_{2}$ & 0 & 0 & 0 & 0 & 0 & 0 & 0.219 & 0.228 & 0.257 & 0.244 & 0.249 & 0.255 & 0.202 & 0.283 & 0.233 & 0.235 & 0.230 \\
\hline$A_{3}$ & 0 & 0 & 0 & 0 & 0 & 0 & 0.179 & 0.185 & 0.172 & 0.179 & 0.200 & 0.137 & 0.186 & 0.162 & 0.159 & 0.182 & 0.153 \\
\hline$A_{4}$ & 0 & 0 & 0 & 0 & 0 & 0 & 0.229 & 0.219 & 0.161 & 0.171 & 0.154 & 0.214 & 0.209 & 0.204 & 0.222 & 0.182 & 0.230 \\
\hline$A_{5}$ & 0 & 0 & 0 & 0 & 0 & 0 & 0.143 & 0.181 & 0.199 & 0.148 & 0.138 & 0.145 & 0.186 & 0.162 & 0.159 & 0.201 & 0.158 \\
\hline Goal & 0 & 0 & 0 & 0 & 0 & 0 & 0 & 0 & 0 & 0 & 0 & 0 & 0 & 0 & 0 & 0 & 0 \\
\hline
\end{tabular}

tal sustainability and human resources factors. Therefore, decision-makers in construction risk management must consider the impact of all risk factors when responding to the safety risk factor.

As mentioned earlier, the aims of this paper are to assess the overall construction risks and prioritize construction project alternatives by considering interrelationships among risk factors. The limited supermatrix is utilized to achieve the mentioned aims. The results of fuzzy DEMATEL-fuzzy ANP determine the final weights of construc- tion risk factors. According to the results of the limited supermatrix reported in Table 11, time, cost and safety factors are identified as the most critical and important construction risks, since they are achieved relatively higher weight values rather than other risk factors. On the other hands, experts are more concerned about these risk factors. According to the experts' opinions, weakness in the construction schedule $\left(C_{11}\right)$ with the weight value of 0.064 has higher value rather than another sub-factor of time risk and can impose the high level of risk in construction 
Continued Table 10

\begin{tabular}{|c|c|c|c|c|c|c|c|c|c|c|c|c|c|c|c|c|c|}
\hline & $C_{41}$ & $C_{42}$ & $C_{43}$ & $C_{51}$ & $C_{52}$ & $C_{53}$ & $C_{54}$ & $C_{61}$ & $C_{62}$ & $C_{63}$ & $C_{64}$ & $A_{1}$ & $A_{2}$ & $A_{3}$ & $A_{4}$ & $A_{5}$ & Goal \\
\hline$C_{1}$ & 0 & 0 & 0 & 0 & 0 & 0 & 0 & 0 & 0 & 0 & 0 & 0 & 0 & 0 & 0 & 0 & 0.343 \\
\hline$C_{2}$ & 0 & 0 & 0 & 0 & 0 & 0 & 0 & 0 & 0 & 0 & 0 & 0 & 0 & 0 & 0 & 0 & 0.233 \\
\hline$C_{3}$ & 0 & 0 & 0 & 0 & 0 & 0 & 0 & 0 & 0 & 0 & 0 & 0 & 0 & 0 & 0 & 0 & 0.092 \\
\hline$C_{4}$ & 0 & 0 & 0 & 0 & 0 & 0 & 0 & 0 & 0 & 0 & 0 & 0 & 0 & 0 & 0 & 0 & 0.208 \\
\hline$C_{5}$ & 0 & 0 & 0 & 0 & 0 & 0 & 0 & 0 & 0 & 0 & 0 & 0 & 0 & 0 & 0 & 0 & 0.065 \\
\hline$C_{6}$ & 0 & 0 & 0 & 0 & 0 & 0 & 0 & 0 & 0 & 0 & 0 & 0 & 0 & 0 & 0 & 0 & 0.059 \\
\hline$C_{11}$ & 0 & 0 & 0 & 0 & 0 & 0 & 0 & 0.504 & 0.537 & 0.538 & 0.510 & 0 & 0 & 0 & 0 & 0 & 0 \\
\hline$C_{12}$ & 0 & 0 & 0 & 0 & 0 & 0 & 0 & 0.496 & 0.463 & 0.462 & 0.490 & 0 & 0 & 0 & 0 & 0 & 0 \\
\hline$C_{21}$ & 0.197 & 0.217 & 0.213 & 0 & 0 & 0 & 0 & 0.218 & 0.216 & 0.223 & 0.241 & 0 & 0 & 0 & 0 & 0 & 0 \\
\hline$C_{22}$ & 0.191 & 0.175 & 0.195 & 0 & 0 & 0 & 0 & 0.189 & 0.189 & 0.201 & 0.186 & 0 & 0 & 0 & 0 & 0 & 0 \\
\hline$C_{23}$ & 0.222 & 0.221 & 0.203 & 0 & 0 & 0 & 0 & 0.224 & 0.220 & 0.233 & 0.206 & 0 & 0 & 0 & 0 & 0 & 0 \\
\hline$C_{24}$ & 0.206 & 0.204 & 0.205 & 0 & 0 & 0 & 0 & 0.189 & 0.208 & 0.228 & 0.227 & 0 & 0 & 0 & 0 & 0 & 0 \\
\hline$C_{25}$ & 0.184 & 0.183 & 0.184 & 0 & 0 & 0 & 0 & 0.181 & 0.168 & 0.115 & 0.140 & 0 & 0 & 0 & 0 & 0 & 0 \\
\hline$C_{31}$ & 0 & 0 & 0 & 0.241 & 0.269 & 0.265 & 0.269 & 0 & 0 & 0 & 0 & 0 & 0 & 0 & 0 & 0 & 0 \\
\hline$C_{32}$ & 0 & 0 & 0 & 0.252 & 0.228 & 0.261 & 0.256 & 0 & 0 & 0 & 0 & 0 & 0 & 0 & 0 & 0 & 0 \\
\hline$C_{33}$ & 0 & 0 & 0 & 0.260 & 0.255 & 0.229 & 0.253 & 0 & 0 & 0 & 0 & 0 & 0 & 0 & 0 & 0 & 0 \\
\hline$C_{34}$ & 0 & 0 & 0 & 0.248 & 0.248 & 0.244 & 0.222 & 0 & 0 & 0 & 0 & 0 & 0 & 0 & 0 & 0 & 0 \\
\hline$C_{41}$ & 0 & 0 & 0 & 0.297 & 0.323 & 0.323 & 0.238 & 0.245 & 0.302 & 0.284 & 0.413 & 0 & 0 & 0 & 0 & 0 & 0 \\
\hline$C_{42}$ & 0 & 0 & 0 & 0.337 & 0.312 & 0.340 & 0.357 & 0.511 & 0.354 & 0.541 & 0.482 & 0 & 0 & 0 & 0 & 0 & 0 \\
\hline$C_{43}$ & 0 & 0 & 0 & 0.366 & 0.364 & 0.336 & 0.405 & 0.244 & 0.344 & 0.175 & 0.105 & 0 & 0 & 0 & 0 & 0 & 0 \\
\hline$C_{51}$ & 0 & 0 & 0 & 0 & 0 & 0 & 0 & 0 & 0 & 0 & 0 & 0 & 0 & 0 & 0 & 0 & 0 \\
\hline$C_{52}$ & 0 & 0 & 0 & 0 & 0 & 0 & 0 & 0 & 0 & 0 & 0 & 0 & 0 & 0 & 0 & 0 & 0 \\
\hline$C_{53}$ & 0 & 0 & 0 & 0 & 0 & 0 & 0 & 0 & 0 & 0 & 0 & 0 & 0 & 0 & 0 & 0 & 0 \\
\hline$C_{54}$ & 0 & 0 & 0 & 0 & 0 & 0 & 0 & 0 & 0 & 0 & 0 & 0 & 0 & 0 & 0 & 0 & 0 \\
\hline$C_{61}$ & 0 & 0 & 0 & 0 & 0 & 0 & 0 & 0 & 0 & 0 & 0 & 0 & 0 & 0 & 0 & 0 & 0 \\
\hline$C_{62}$ & 0 & 0 & 0 & 0 & 0 & 0 & 0 & 0 & 0 & 0 & 0 & 0 & 0 & 0 & 0 & 0 & 0 \\
\hline$C_{63}$ & 0 & 0 & 0 & 0 & 0 & 0 & 0 & 0 & 0 & 0 & 0 & 0 & 0 & 0 & 0 & 0 & 0 \\
\hline$C_{64}$ & 0 & 0 & 0 & 0 & 0 & 0 & 0 & 0 & 0 & 0 & 0 & 0 & 0 & 0 & 0 & 0 & 0 \\
\hline$A_{1}$ & 0.232 & 0.240 & 0.246 & 0.178 & 0.242 & 0.206 & 0.225 & 0.224 & 0.208 & 0.222 & 0.238 & 0 & 0 & 0 & 0 & 0 & 0 \\
\hline$A_{2}$ & 0.213 & 0.224 & 0.264 & 0.256 & 0.216 & 0.243 & 0.241 & 0.216 & 0.253 & 0.194 & 0.245 & 0 & 0 & 0 & 0 & 0 & 0 \\
\hline$A_{3}$ & 0.178 & 0.157 & 0.159 & 0.181 & 0.153 & 0.168 & 0.177 & 0.197 & 0.189 & 0.183 & 0.175 & 0 & 0 & 0 & 0 & 0 & 0 \\
\hline$A_{4}$ & 0.220 & 0.245 & 0.165 & 0.230 & 0.247 & 0.241 & 0.234 & 0.224 & 0.189 & 0.227 & 0.193 & 0 & 0 & 0 & 0 & 0 & 0 \\
\hline$A_{5}$ & 0.157 & 0.134 & 0.165 & 0.155 & 0.142 & 0.143 & 0.123 & 0.139 & 0.162 & 0.173 & 0.149 & 0 & 0 & 0 & 0 & 0 & 0 \\
\hline Goal & 0 & 0 & 0 & 0 & 0 & 0 & 0 & 0 & 0 & 0 & 0 & 1 & 1 & 1 & 1 & 1 & 0 \\
\hline
\end{tabular}

projects, since it is a causal factor and affects cost, quality, and safety risks. Therefore, to avoid this risk, project managers and engineers must provide an appropriate project schedule planning and an effective schedule control methodology, since the successful execution of a construction project depends on the schedule planning and control.

The high price of tender $\left(C_{21}\right)$ and delay in payment of costs according to the contract $\left(C_{24}\right)$ with the weight values of 0.039 and 0.036 are the most important factors in cost risk, respectively. As cost risks are identified as a caus- al factor which has major interactions with other risk factors, providing appropriate actions to eliminate or mitigate the negative impacts of these risks is highly recommended. The reason for the high price of bidding may be unfair or unprofessional bidding practices, which is directly related to the designers' knowledge (Taylan et al., 2014). Selection of qualified and experienced designers, precise estimation of cost items and the proper cost management will help managers to propose a reasonable price of tender. Also, timely financial support of government and investors can 
Table 11. Limited supermatrix

\begin{tabular}{|c|c|c|c|c|c|c|c|c|c|c|c|c|c|c|c|c|c|}
\hline & $C_{1}$ & $C_{2}$ & $C_{3}$ & $C_{4}$ & $C_{5}$ & $C_{6}$ & $C_{11}$ & $C_{12}$ & $C_{21}$ & $C_{22}$ & $\cdots$ & $\cdots$ & $\cdots$ & $\cdots$ & $A_{4}$ & $A_{5}$ & Goal \\
\hline$C_{1}$ & 0.056 & 0.056 & 0.056 & 0.056 & 0.056 & 0.056 & 0.056 & 0.056 & 0.056 & 0.056 & $\cdots$ & $\cdots$ & $\cdots$ & $\cdots$ & 0.056 & 0.056 & 0.056 \\
\hline$C_{2}$ & 0.038 & 0.038 & 0.038 & 0.038 & 0.038 & 0.038 & 0.038 & 0.038 & 0.038 & 0.038 & $\cdots$ & $\cdots$ & $\cdots$ & $\cdots$ & 0.038 & 0.038 & 0.038 \\
\hline$C_{3}$ & 0.015 & 0.015 & 0.015 & 0.015 & 0.015 & 0.015 & 0.015 & 0.015 & 0.015 & 0.015 & $\cdots$ & $\cdots$ & $\ldots$ & $\cdots$ & 0.015 & 0.015 & 0.015 \\
\hline$C_{4}$ & 0.034 & 0.034 & 0.034 & 0.034 & 0.034 & 0.034 & 0.034 & 0.034 & 0.034 & 0.034 & $\ldots$ & $\ldots$ & $\ldots$ & $\ldots$ & 0.034 & 0.034 & 0.034 \\
\hline$C_{6}$ & 0.010 & 0.010 & 0.010 & 0.010 & 0.010 & 0.010 & 0.010 & 0.010 & 0.010 & 0.010 & $\cdots$ & $\cdots$ & $\cdots$ & $\cdots$ & 0.010 & 0.010 & 0.010 \\
\hline$C_{11}$ & 0.064 & 0.064 & 0.064 & 0.064 & 0.064 & 0.064 & 0.064 & 0.064 & 0.064 & 0.064 & $\cdots$ & $\cdots$ & $\cdots$ & $\cdots$ & 0.064 & 0.064 & 0.064 \\
\hline$C_{12}$ & 0.026 & 0.026 & 0.026 & 0.026 & 0.026 & 0.026 & 0.026 & 0.026 & 0.026 & 0.026 & $\cdots$ & $\ldots$ & $\ldots$ & $\ldots$ & 0.026 & 0.026 & 0.026 \\
\hline$C_{21}$ & 0.039 & 0.039 & 0.039 & 0.039 & 0.039 & 0.039 & 0.039 & 0.039 & 0.039 & 0.039 & $\cdots$ & $\cdots$ & $\ldots$ & $\cdots$ & 0.039 & 0.039 & 0.039 \\
\hline$C_{23}$ & 0.027 & 0.027 & 0.027 & 0.027 & 0.027 & 0.027 & 0.027 & 0.027 & 0.027 & 0.027 & $\cdots$ & $\cdots$ & $\ldots$ & $\ldots$ & 0.027 & 0.027 & 0.027 \\
\hline$C_{24}$ & 0.036 & 0.036 & 0.036 & 0.036 & 0.036 & 0.036 & 0.036 & 0.036 & 0.036 & 0.036 & $\cdots$ & $\cdots$ & $\cdots$ & $\cdots$ & 0.036 & 0.036 & 0.036 \\
\hline$C_{25}$ & 0.024 & 0.024 & 0.024 & 0.024 & 0.024 & 0.024 & 0.024 & 0.024 & 0.024 & 0.024 & $\cdots$ & $\cdots$ & $\cdots$ & $\cdots$ & 0.024 & 0.024 & 0.024 \\
\hline$C_{31}$ & 0.019 & 0.019 & 0.019 & 0.019 & 0.019 & 0.019 & 0.019 & 0.019 & 0.019 & 0.019 & $\cdots$ & $\cdots$ & $\cdots$ & $\cdots$ & 0.019 & 0.019 & 0.019 \\
\hline$C_{32}$ & 0.021 & 0.021 & 0.021 & 0.021 & 0.021 & 0.021 & 0.021 & 0.021 & 0.021 & 0.021 & $\cdots$ & $\cdots$ & $\cdots$ & $\cdots$ & 0.021 & 0.021 & 0.021 \\
\hline$C_{33}$ & 0.023 & 0.023 & 0.023 & 0.023 & 0.023 & 0.023 & 0.023 & 0.023 & 0.023 & 0.023 & $\cdots$ & $\cdots$ & $\cdots$ & $\cdots$ & 0.023 & 0.023 & 0.023 \\
\hline$C_{34}$ & 0.019 & 0.019 & 0.019 & 0.019 & 0.019 & 0.019 & 0.019 & 0.019 & 0.019 & 0.019 & $\cdots$ & $\cdots$ & $\cdots$ & $\cdots$ & 0.019 & 0.019 & 0.019 \\
\hline$C_{41}$ & 0.054 & 0.054 & 0.054 & 0.054 & 0.054 & 0.054 & 0.054 & 0.054 & 0.054 & 0.054 & $\cdots$ & $\cdots$ & $\cdots$ & $\cdots$ & 0.054 & 0.054 & 0.054 \\
\hline$C_{42}$ & 0.039 & 0.039 & 0.039 & 0.039 & 0.039 & 0.039 & 0.039 & 0.039 & 0.039 & 0.039 & $\cdots$ & $\cdots$ & $\cdots$ & $\cdots$ & 0.039 & 0.039 & 0.039 \\
\hline$C_{43}$ & 0.038 & 0.038 & 0.038 & 0.038 & 0.038 & 0.038 & 0.038 & 0.038 & 0.038 & 0.038 & $\cdots$ & $\cdots$ & $\cdots$ & $\cdots$ & 0.038 & 0.038 & 0.038 \\
\hline$C_{52}$ & 0.007 & 0.007 & 0.007 & 0.007 & 0.007 & 0.007 & 0.007 & 0.007 & 0.007 & 0.007 & $\cdots$ & $\cdots$ & $\cdots$ & $\cdots$ & 0.007 & 0.007 & 0.007 \\
\hline$C_{53}$ & 0.016 & 0.016 & 0.016 & 0.016 & 0.016 & 0.016 & 0.016 & 0.016 & 0.016 & 0.016 & $\cdots$ & $\cdots$ & $\cdots$ & $\cdots$ & 0.016 & 0.016 & 0.016 \\
\hline$C_{54}$ & 0.009 & 0.009 & 0.009 & 0.009 & 0.009 & 0.009 & 0.009 & 0.009 & 0.009 & 0.009 & $\cdots$ & $\cdots$ & $\cdots$ & $\cdots$ & 0.009 & 0.009 & 0.009 \\
\hline$C_{61}$ & 0.003 & 0.003 & 0.003 & 0.003 & 0.003 & 0.003 & 0.003 & 0.003 & 0.003 & 0.003 & $\cdots$ & $\cdots$ & $\cdots$ & $\cdots$ & 0.003 & 0.003 & 0.003 \\
\hline$C_{62}$ & 0.001 & 0.001 & 0.001 & 0.001 & 0.001 & 0.001 & 0.001 & 0.001 & 0.001 & 0.001 & $\cdots$ & $\cdots$ & $\cdots$ & $\cdots$ & 0.001 & 0.001 & 0.001 \\
\hline$C_{63}$ & 0.004 & 0.004 & 0.004 & 0.004 & 0.004 & 0.004 & 0.004 & 0.004 & 0.004 & 0.004 & $\cdots$ & $\cdots$ & $\cdots$ & $\cdots$ & 0.004 & 0.004 & 0.004 \\
\hline$C_{64}$ & 0.001 & 0.001 & 0.001 & 0.001 & 0.001 & 0.001 & 0.001 & 0.001 & 0.001 & 0.001 & $\cdots$ & $\cdots$ & $\cdots$ & $\cdots$ & 0.001 & 0.001 & 0.001 \\
\hline$A_{1}$ & 0.037 & 0.037 & 0.037 & 0.037 & 0.037 & 0.037 & 0.037 & 0.037 & 0.037 & 0.037 & $\cdots$ & $\cdots$ & $\cdots$ & $\cdots$ & 0.037 & 0.037 & 0.037 \\
\hline$A_{2}$ & 0.038 & 0.038 & 0.038 & 0.038 & 0.038 & 0.038 & 0.038 & 0.038 & 0.038 & 0.038 & $\ldots$ & $\ldots$ & $\ldots$ & $\ldots$ & 0.038 & 0.038 & 0.038 \\
\hline$A_{3}$ & 0.028 & 0.028 & 0.028 & 0.028 & 0.028 & 0.028 & 0.028 & 0.028 & 0.028 & 0.028 & $\cdots$ & $\cdots$ & $\cdots$ & $\cdots$ & 0.028 & 0.028 & 0.028 \\
\hline$A_{4}$ & 0.034 & 0.034 & 0.034 & 0.034 & 0.034 & 0.034 & 0.034 & 0.034 & 0.034 & 0.034 & $\cdots$ & $\cdots$ & $\cdots$ & $\cdots$ & 0.034 & 0.034 & 0.034 \\
\hline$A_{5}$ & 0.026 & 0.026 & 0.026 & 0.026 & 0.026 & 0.026 & 0.026 & 0.026 & 0.026 & 0.026 & $\cdots$ & $\cdots$ & $\cdots$ & $\cdots$ & 0.026 & 0.026 & 0.026 \\
\hline Goal & 0.163 & 0.163 & 0.163 & 0.163 & 0.163 & 0.163 & 0.163 & 0.163 & 0.163 & 0.163 & $\cdots$ & $\cdots$ & $\cdots$ & $\cdots$ & 0.163 & 0.163 & 0.163 \\
\hline
\end{tabular}

Table 12. The final weights of risk factors obtained by fuzzy DEMATEL-fuzzy ANP and fuzzy AHP

\begin{tabular}{|l|c|c|c|c|}
\hline & \multicolumn{2}{|c|}{ Fuzzy DEMATEL-fuzzy ANP } & \multicolumn{2}{c|}{ Fuzzy AHP (Taylan et al., 2014) } \\
\hline & Final weight & Rank & Final weight & Rank \\
\hline Time risk & 0.056 & 1 & 0.493 & 1 \\
Cost risk & 0.038 & 2 & 0.337 & 2 \\
Quality risk & 0.015 & 4 & 0.203 & 3 \\
Safety risk & 0.034 & 3 & 0.080 & 4 \\
Environmental Sustainability Risk & 0.011 & 5 & 0.067 & 5 \\
Human Resources Risk & 0.010 & 6 & - & - \\
\hline
\end{tabular}


delete or decrease the negative impacts of the risk factor of "delay in payment of costs according to contract" in construction projects.

Collapse with the weight value of 0.04 is the most important safety risk factor. The collapse has serious injuries and fatalities as well as negative financial impacts, every year. Obtaining safety policies and safety training significantly reduce unnecessary accidents in the workplace. To avoid the safety risks in the building projects, project managers and policy makers can provide a convenient safety program that obtains daily and weekly safety information and reminders to the workforce.

The final weights of alternatives help us to evaluate the efficiency rate of construction projects (Taylan et al., 2014). The construction project with the highest weight value is considered to be the one which has the highest risk. Recreational and Commercial Complex of Negin Chargagh $\left(A_{2}\right)$ with the weight value of 0.038 has the highest efficiency rate. Therefore, it is the highest risk category project. Sepahan Recreational and Commercial Complex $\left(A_{1}\right)$ and Recreational, Commercial, and Administrative Complex of Anoushirvan $\left(A_{4}\right)$ have the weight values of 0.037 and 0.034 , respectively. They gained the second and third efficiency rates among alternatives and carried the second and third order high-risk levels, respectively. Finally, according to the values of weight of Recreational, Servicing, and Commercial Complex of Goldasteh Garden $\left(A_{5}\right)$ and Recreational, Tourism, and Commercial Complex of Fadak Center $\left(A_{3}\right)$, they are considered as the lowest risk category projects, respectively.

\section{Conclusions}

In this research, the integrated fuzzy DEMATEL-fuzzy ANP model was used for evaluating construction projects based on the dependencies among risk factors. For this purpose, the risk factors affecting the performance of construction projects were initially identified and finalized through the literature review and the experts' opinions. According to the past studies, five main risk factors including time, cost, quality, safety, environmental Sustainability risks and a new factor named human resources risk were selected to evaluate construction projects. Since there are interrelationships between risk factors, the fuzzy DEMATEL method was used to identify the interrelations among risk factors. The results of fuzzy DEMATEL revealed that the risk factors have significant effects on each other. For instance, the human resources risk affects the time, cost and safety in construction projects. The network structure for applying fuzzy ANP was extracted according to the results of fuzzy DEMATEL. According to the network structure, several pairwise comparisons were performed to calculate the local weights of the risk criteria, their sub-criteria, and alternatives. Finally, fuzzy ANP was employed to determine the final weights of the main risk factors and alternatives. The results of fuzzy DEMATEL-fuzzy ANP revealed that the time, cost and safety are the most important risk factors in construction projects. These results show that experts are more concerned about these risk factors in construction projects, since their final weights are significantly higher than the weights of other risk factors. The results of fuzzy DEMATEL-fuzzy ANP are validated by the fuzzy AHP results reported by Taylan et al. (2014). The final weights of the construction project alternatives extracted from limited supermatrix were then used to evaluate the efficiency rate of construction projects and select the highest risk category project. According to the results, Recreational and Commercial Complex of Negin Chargagh $\left(A_{2}\right)$ gained the highest efficiency rate and determined as the highest risk category project.

In this paper, the criteria determine the importance of construction project alternatives. It needs to be additionally considered whether or not the alternatives incidentally determine the importance of the criteria. Therefore, it is recommended that the feedback between criteria and alternatives to be considered for the evaluation and selection of the projects in the future research.

\section{Acknowledgements}

The authors are grateful to the respected reviewers for their constructive and valuable comments in preparation of the revised manuscript.

\section{Author contributions}

Seyed Morteza Hatefi is responsible for providing an appropriate method, designing the research and methodology, collecting and analyzing the data and the obtained results. Jolanta Tamošaitiene provided extensive advice throughout the study and is responsible for research design, finalizing the initial draft of the paper and revising the manuscript.

\section{Funding}

We didn’t utilize any funding to perform this research.

\section{Disclosure statement}

We don't have any competing financial, professional, or personal interests from other parties.

\section{References}

Büyüközkan, G., \& Çifçi, G. (2012). A novel hybrid MCDM approach based on fuzzy DEMATEL, fuzzy ANP and fuzzy TOPSIS to evaluate green suppliers. Expert Systems with Applications, 39(3), 3000-3011.

https://doi.org/10.1016/j.eswa.2011.08.162

Chatterjee, K., Zavadskas, E. K., Tamošaitiene, J., Adhikary, K., \& Kar, S. (2018). A Hybrid MCDM technique for risk Management in construction projects. Symmetry, 10(2), 46. https://doi.org/10.3390/sym10020046

Chau Ngoc, D., Long, L. H., Soo-Yong, K., Chau Van, N., YoungDai, L., \& Sun-Ho, L. (2017). Identification of risk patterns in 
Vietnamese road and bridge construction: Contractor's perspective. Built Environment Project and Asset Management, 7(1), 59-72. https://doi.org/10.1108/BEPAM-11-2015-0065

Chien, K. F., Wu, Z. H., \& Huang, S. C. (2014). Identifying and assessing critical risk factors for BIM projects: Empirical study. Automation in Construction, 45, 1-15.

https://doi.org/10.1016/j.autcon.2014.04.012

Ebrahimnejad, S., Mousavi, S. M., Tavakkoli-Moghaddam, R., Hashemi, H., \& Vahdani, B. (2012). A novel two-phase group decision making approach for construction project selection in a fuzzy environment. Applied Mathematical Modelling, 36(9), 4197-4217. https://doi.org/10.1016/j.apm.2011.11.050

El-Sayegh, S. M., \& Mansour, M. H. (2015). Risk assessment and allocation in highway construction projects in the UAE. Journal of Management in Engineering, 31(6), 15-22. https://doi.org/10.1061/(ASCE)ME.1943-5479.0000365

Flanagan, R., \& Norman, G. (1993). Risk management and construction. Victoria: Blackwell, Science Pty Ltd.

Gabus, A., \& Fontela, E. (1972). World problems, an invitation to further thought within the framework of DEMATEL. Geneva: Battelle Geneva Research Center.

Ghasemi, F., Sari, M. H. M., Yousefi, V., Falsafi, R., \& Tamošaitiene, J. (2018). Project portfolio risk identification and analysis, considering project risk interactions and using Bayesian networks. Sustainability, 10(5), 1609. https://doi.org/10.3390/su10051609

Iqbal, S., Choudhry, R. M., Holschemacher, K., Ali, A., \& Tamošaitienė, J. (2015). Risk management in construction projects. Technological and Economic Development of Economy, 21(1), 65-78. https://doi.org/10.3846/20294913.2014.994582

Islam, M. S., Nepal, M. P., Skitmore, M., \& Attarzadeh, M. (2017). Current research trends and application areas of fuzzy and hybrid methods to the risk assessment of construction projects. Advanced Engineering Informatics, 33, 112-131. https://doi.org/10.1016/j.aei.2017.06.001

Jeng, D. J. F., \& Tzeng, G. H. (2012). Social influence on the use of clinical decision support systems: Revisiting the unified theory of acceptance and use of technology by the fuzzy DEMATEL technique. Computers \& Industrial Engineering, 62(3), 819-828. https://doi.org/10.1016/j.cie.2011.12.016

KarimiAzari, A., Mousavi, N., Mousavi, S. F., \& Hosseini, S. (2011). Risk assessment model selection in construction industry. Expert Systems with Applications, 38(8), 9105-9111. https://doi.org/10.1016/j.eswa.2010.12.110

Leung, L. C., \& Cao, D. (2000). On consistency and ranking of alternatives in fuzzy AHP. European Journal of Operational Research, 124, 102-113. https://doi.org/10.1016/S0377-2217(99)00118-6

Liang, H., Ren, J., Gao, Z., Gao, S., Luo, X., Dong, L., \& Scipioni, A. (2016). Identification of critical success factors for sustainable development of biofuel industry in China based on grey decision-making trial and evaluation laboratory (DEMATEL). Journal of Cleaner Production, 131, 500-508. https://doi.org/10.1016/j.jclepro.2016.04.151

Lin, C., \& Wu, W. (2008). A causal analytical method for group decision-making under fuzzy environment. Expert Systems with Applications, 34(1), 205-213.

https://doi.org/10.1016/j.eswa.2006.08.012

Liou, J. J. H., Tamošaitienė, J., Zavadskas, E. K., \& Tzeng, G.-H. (2016). New hybrid COPRAS-G MADM Model for improving and selecting suppliers in green supply chain management. International Journal of Production Research, 54(1), 114-134. https://doi.org/10.1080/00207543.2015.1010747
Nieto-Morote, A., \& Ruz-Vila, F. (2011). A fuzzy approach to construction project risk assessment. International Journal of Project Management, 29(2), 220-231.

https://doi.org/10.1016/j.ijproman.2010.02.002

Opricovic, S., \& Tzeng, G. (2003). Defuzzification within a multicriteria decision model. International Journal of Uncertainty, Fuzziness and Knowledge-Based Systems, 11, 635-652. https://doi.org/10.1142/S0218488503002387

Özdemir, A., \& Tüysüz, F. (2017). An integrated fuzzy DEMATEL and fuzzy ANP based balanced scorecard approach: application in Turkish higher education institutions. Journal of Multiple-Valued Logic \& Soft Computing, 28(2/3), 251-287.

Ren, J., \& Sovacool, B. K. (2014). Quantifying, measuring, and strategizing energy security: Determining the most meaningful dimensions and metrics. Energy, 76, 838-849.

https://doi.org/10.1016/j.energy.2014.08.083

Saaty, T. L. (1996). The analytic network process. Pittsburgh: RWS Publications.

Saaty, T. L. (2005). Theory and applications of the analytic network process decision making with benefits, opportunities, costs and risks. Pittsburgh: RWS Publications.

Samantra, C., Datta, S., \& Mahapatra, S. S. (2017). Fuzzy based risk assessment module for metropolitan construction project: An empirical study. Engineering Applications of Artificial Intelligence, 65, 449-464. https://doi.org/10.1016/j.engappai.2017.04.019

Seker, S., \& Zavadskas, E. K. (2017). Application of fuzzy DEMATEL method for analyzing occupational risks on construction sites. Sustainability, 9, 2083. https://doi.org/10.3390/su9112083

Tah, J. H. M., \& Carr, V. (2000). A proposal for construction project risk assessment using fuzzy logic. Construction Management and Economics, 18(4), 491-500. https://doi.org/10.1080/01446190050024905

Tamošaitienè, J., Turskis, Z., \& Zavadskas, E. K. (2008). Modeling of contractor selection taking into account different risk level. In The $25^{\text {th }}$ International Symposium on Automation and Robotics in Construction (ISARC 2008) (pp. 676-681). https://doi.org/10.22260/ISARC2008/0099

Tamošaitiene, J., Zavadskas, E. K., \& Turskis, Z. (2013). Multicriteria risk assessment of a construction project. Procedia Computer Science, 17, 129-133. https://doi.org/10.1016/j.procs.2013.05.018

Taylan, O., Bafail, A. O., Abdulaal, R. M. S., \& Kabli, M. R. (2014). Construction projects selection and risk assessment by fuzzy AHP and fuzzy TOPSIS methodologies. Applied Soft Computing, 17, 105-116.

https://doi.org/10.1016/j.asoc.2014.01.003

Tsai, S. B., Chien, M. F., Xue, Y., Li, L., Jiang, X., Chen, Q., \& Wang, L. (2015). Using the fuzzy DEMATEL to determine environmental performance: A case of printed circuit board industry in Taiwan. PLOS ONE, 10(6), 0129153. https://doi.org/10.1371/journal.pone.0129153

Tseng, M. L. (2011). Using a hybrid MCDM model to evaluate firm environmental knowledge management in uncertainty. Applied Soft Computing, 11(1), 1340-1352. https://doi.org/10.1016/j.asoc.2010.04.006

Tzeng, G., Chiang, C., \& Li, C. (2007). Evaluating intertwined effects in e-learning programs: A novel hybrid MCDM model based on factor analysis and DEMATEL. Expert Systems with Applications, 32(4), 1028-1044.

https://doi.org/10.1016/j.eswa.2006.02.004

Uygun, Ö., \& Dede, A. (2016). Performance evaluation of green supply chain management using integrated fuzzy multi-cri- 
teria decision making techniques. Computers \& Industrial Engineering, 102, 502-511.

https://doi.org/10.1016/j.cie.2016.02.020

Valipour, A., Yahaya, N., Noor, N. Md., Antuchevičienė, J., \& Tamošaitienè, J. (2017). Hybrid SWARA-COPRAS method for risk assessment in deep foundation excavation project: an Iranian case study. Journal of Civil Engineering and Management, 23(4), 524-532.

https://doi.org/10.3846/13923730.2017.1281842

Wang, T., Wang, S., Zhang, L., Huang, Z., \& Li, Y. (2016). A major infrastructure risk-assessment framework: Application to a cross-sea route project in China. International Journal of Project Management, 34(7), 1403-1415.

https://doi.org/10.1016/j.ijproman.2015.12.006

Wei, W. W., \& Yu, T. L. (2007). Developing global managers' competencies using the fuzzy DEMATEL method. Expert
Systems with Applications, 32(2), 499-507. https://doi.org/10.1016/j.eswa.2005.12.005

Winch, G. (2002). Managing construction projects: An information processing approach. Wiley.

Yazdani-Chamzini, A. (2014). Proposing a new methodology based on fuzzy logic for tunneling risk assessment. Journal of Civil Engineering and Management, 20(1), 82-94.

https://doi.org/10.3846/13923730.2013.843583

Zavadskas, E. K., Turskis, Z., \& Tamošaitienè, J. (2010). Risk assessment of construction projects. Journal of Civil Engineering and Management, 16(1), 33-46.

https://doi.org/10.3846/jcem.2010.03

Zhou, J. L., Bai, Z. H., \& Sun, Z. Y. (2014). A hybrid approach for safety assessment in high-risk hydropower-constructionproject work systems. Safety Science, 64, 163-172.

https://doi.org/10.1016/j.ssci.2013.12.008

\section{Appendix 1. The fuzzy DEMATEL and fuzzy ANP questionnaires:}

\section{A) Fuzzy DEMATEL questionnaire}

Please specify the effect of the factor in the row on the factor in each column using one of the values (very high $=$ 5 , high $=4$, low $=3$, very low $=2$ and no impact $=1$ ). For example, in the table below, "high" in the Gray part means that the cost risk has high influence on the quality risk.

\section{B) Fuzzy ANP questionnaire}

An example of pairwise comparison of two risk factors in the fuzzy ANP questionnaire is: "Which risk factor is important with respect to your goal and to what degree?"

By a similar way, the pairwise comparison of sub-factors with respect to the main risk factor can be written according to the Table A.1.2. Due to the paper size limit, these tables are not presented here.

The results of fuzzy DEMATEL show that time risk affect the cost risks. Therefore, the sub-factors of cost risks must be compared to each other with respect of each subfactor of time risks. Therefore, here is two pairwise comparison tables.

An example of pairwise comparison of two sub-factors of cost risk in the fuzzy ANP questionnaire is: "Which sub- factor of cost risk is important with respect to "weakness in construction schedule $\left(C_{11}\right)$ " to what degree?"

By a similar way, the pairwise comparison tables of each case-effect cluster of risk factors can be written according to the Table A.1.3. Due to the paper size limit, these tables are not presented here.

Finally, the pairwise comparison of construction project alternatives with respect to each of sub-factor of risks can be obtained according to the Table A.1.4.

\section{Construction projects alternatives:}

- Sepahan Recreational and Commercial Complex $\left(A_{1}\right)$;

- Recreational and Commercial Complex of Negin Chargagh $\left(A_{2}\right)$;

- Recreational, Tourism, and Commercial Complex of Fadak Center $\left(A_{3}\right)$;

- Recreational, Commercial, and Administrative Complex of Anoushirvan $\left(A_{4}\right)$;

- Recreational, Servicing, and Commercial Complex of Goldasteh Garden $\left(A_{5}\right)$.

Table A.1.1. Fuzzy DEMATEL questionnaire

\begin{tabular}{|l|c|c|c|c|c|c|}
\hline & $\begin{array}{c}\text { Time risk } \\
\left(C_{1}\right)\end{array}$ & $\begin{array}{c}\text { Cost risk } \\
\left(C_{2}\right)\end{array}$ & $\begin{array}{c}\text { Quality risk } \\
\left(C_{3}\right)\end{array}$ & $\begin{array}{c}\text { Safety risk } \\
\left(C_{4}\right)\end{array}$ & $\begin{array}{c}\text { Environmental } \\
\text { sustainability risk }\left(C_{5}\right)\end{array}$ & $\begin{array}{c}\text { Human } \\
\text { resources } \\
\text { risk }\left(C_{6}\right)\end{array}$ \\
\hline Time risk $\left(C_{1}\right)$ & $*$ & & & & & \\
\hline Cost risk $\left(C_{2}\right)$ & & $*$ & "high" & & & \\
\hline Quality risk $\left(C_{3}\right)$ & & & $*$ & & & \\
\hline Safety risk $\left(C_{4}\right)$ & & & & $*$ & & \\
\hline Environmental sustainability risk $\left(C_{5}\right)$ & & & & & & \\
\hline Human resources risk $\left(C_{6}\right)$ & & & & & & $*$ \\
\hline
\end{tabular}


Table A.1.2. Pairwise comparison of the risk factors with respect to goal

\begin{tabular}{|c|c|c|c|c|c|c|c|c|c|c|}
\hline Risk factor & 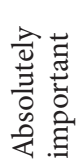 & 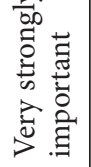 & 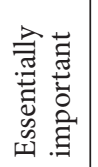 & 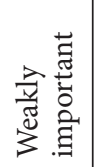 & 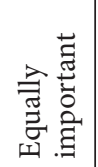 & 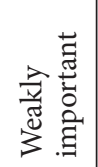 & 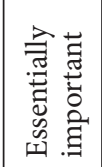 & 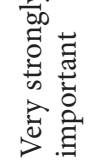 & 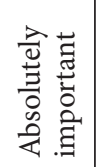 & Risk factor \\
\hline Time risk $\left(C_{1}\right)$ & & & & & & & & & & Cost risk $\left(C_{2}\right)$ \\
\hline Time risk $\left(C_{1}\right)$ & & & & & & & & & & Quality risk $\left(C_{3}\right)$ \\
\hline Time risk $\left(C_{1}\right)$ & & & & & & & & & & Safety risk $\left(C_{4}\right)$ \\
\hline Time risk $\left(C_{1}\right)$ & & & & & & & & & & $\begin{array}{l}\text { Environmental } \\
\text { sustainability risk }\left(C_{5}\right)\end{array}$ \\
\hline Time risk $\left(C_{1}\right)$ & & & & & & & & & & Human resources risk $\left(C_{6}\right)$ \\
\hline Cost risk $\left(C_{2}\right)$ & & & & & & & & & & Quality risk $\left(C_{3}\right)$ \\
\hline Cost risk $\left(C_{2}\right)$ & & & & & & & & & & Safety risk $\left(C_{4}\right)$ \\
\hline Cost risk $\left(C_{2}\right)$ & & & & & & & & & & $\begin{array}{l}\text { Environmental } \\
\text { sustainability risk }\left(C_{5}\right)\end{array}$ \\
\hline Cost risk $\left(C_{2}\right)$ & & & & & & & & & & Human resources risk $\left(C_{6}\right)$ \\
\hline Quality risk $\left(C_{3}\right)$ & & & & & & & & & & Safety risk $\left(C_{4}\right)$ \\
\hline Quality risk $\left(C_{3}\right)$ & & & & & & & & & & $\begin{array}{l}\text { Environmental } \\
\text { sustainability risk }\left(C_{5}\right)\end{array}$ \\
\hline Quality risk $\left(C_{3}\right)$ & & & & & & & & & & Human resources risk $\left(C_{6}\right)$ \\
\hline Safety risk $\left(C_{4}\right)$ & & & & & & & & & & $\begin{array}{l}\text { Environmental } \\
\text { sustainability risk }\left(C_{5}\right)\end{array}$ \\
\hline Safety risk $\left(C_{4}\right)$ & & & & & & & & & & Human resources risk $\left(C_{6}\right)$ \\
\hline $\begin{array}{l}\text { Environmental sustainability } \\
\text { risk }\left(C_{5}\right)\end{array}$ & & & & & & & & & & Human resources risk $\left(C_{6}\right)$ \\
\hline
\end{tabular}

Table A.1.3. Pairwise comparison of sub-factors of cost risk with respect to a) Weakness in construction schedule $\left(C_{11}\right)$ and b) Delay in supply of materials $\left(C_{12}\right)$

\begin{tabular}{|l|l|l|l|l|l|l|l|l|l|l|}
\hline \multicolumn{1}{|c|}{ Sub-factor of cost risk } & Put & Sub-factor of cost risk \\
\hline High price of tender $\left(C_{21}\right)$ & & & & & & & & & & $\begin{array}{l}\text { Increase in materials prices } \\
\left(C_{22}\right)\end{array}$ \\
\hline High price of tender $\left(C_{21}\right)$ & & & & & & & & & & Increase in labor cost $\left(C_{23}\right)$ \\
\hline High price of tender $\left(C_{21}\right)$ & & & & & & & & & & $\begin{array}{l}\text { Delay in payment of costs } \\
\text { according to contract }\left(C_{24}\right)\end{array}$ \\
\hline High price of tender $\left(C_{21}\right)$ & & & & & & & & & & Financial difficulties $\left(C_{25}\right)$ \\
\hline $\begin{array}{l}\text { Increase in materials prices } \\
\left(C_{22}\right)\end{array}$ & & & & & & & & & & Increase in labor cost $\left(C_{23}\right)$ \\
\hline $\begin{array}{l}\text { Increase in materials prices } \\
\left(C_{22}\right)\end{array}$ & & & & & & & & & & $\begin{array}{l}\text { Delay in payment of costs } \\
\text { according to contract }\left(C_{24}\right)\end{array}$ \\
\hline $\begin{array}{l}\text { Increase in materials prices } \\
\left(C_{22}\right)\end{array}$ & & & & & & & & & & Financial difficulties $\left(C_{25}\right)$ \\
\hline Increase in labor cost $\left(C_{23}\right)$ & & & & & & & & & & $\begin{array}{l}\text { Delay in payment of costs } \\
\text { according to contract }\left(C_{24}\right)\end{array}$ \\
\hline Increase in labor cost $\left(C_{23}\right)$ & & & & & & & & & & Financial difficulties $\left(C_{25}\right)$ \\
\hline $\begin{array}{l}\text { Delay in payment of costs } \\
\text { according to contract }\left(C_{24}\right)\end{array}$ & & & & & & & & & & Financial difficulties $\left(C_{25}\right)$ \\
\hline
\end{tabular}


Table A.1.4. Pairwise comparison of construction projects alternatives with respect to each sub-factor of risk

\begin{tabular}{|c|c|c|c|c|c|c|c|c|c|c|}
\hline $\begin{array}{l}\text { Construction } \\
\text { project alternative }\end{array}$ & 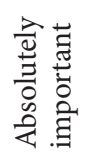 & 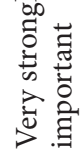 & 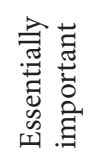 & 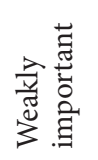 & 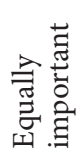 & 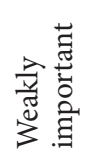 & 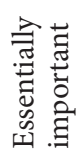 & 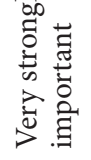 & 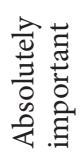 & $\begin{array}{c}\text { Construction } \\
\text { project alternative }\end{array}$ \\
\hline$A_{1}$ & & & & & & & & & & $A_{2}$ \\
\hline$A_{1}$ & & & & & & & & & & $A_{3}$ \\
\hline$A_{1}$ & & & & & & & & & & $A_{4}$ \\
\hline$A_{1}$ & & & & & & & & & & $A_{5}$ \\
\hline$A_{2}$ & & & & & & & & & & $A_{3}$ \\
\hline$A_{2}$ & & & & & & & & & & $A_{4}$ \\
\hline$A_{2}$ & & & & & & & & & & $A_{5}$ \\
\hline$A_{3}$ & & & & & & & & & & $A_{4}$ \\
\hline$A_{3}$ & & & & & & & & & & $A_{5}$ \\
\hline$A_{4}$ & & & & & & & & & & $A_{5}$ \\
\hline
\end{tabular}

\section{Appendix 2. The respected codes in SPLUS software}

\section{A) The code for defuzzification of a fuzzy matrix}

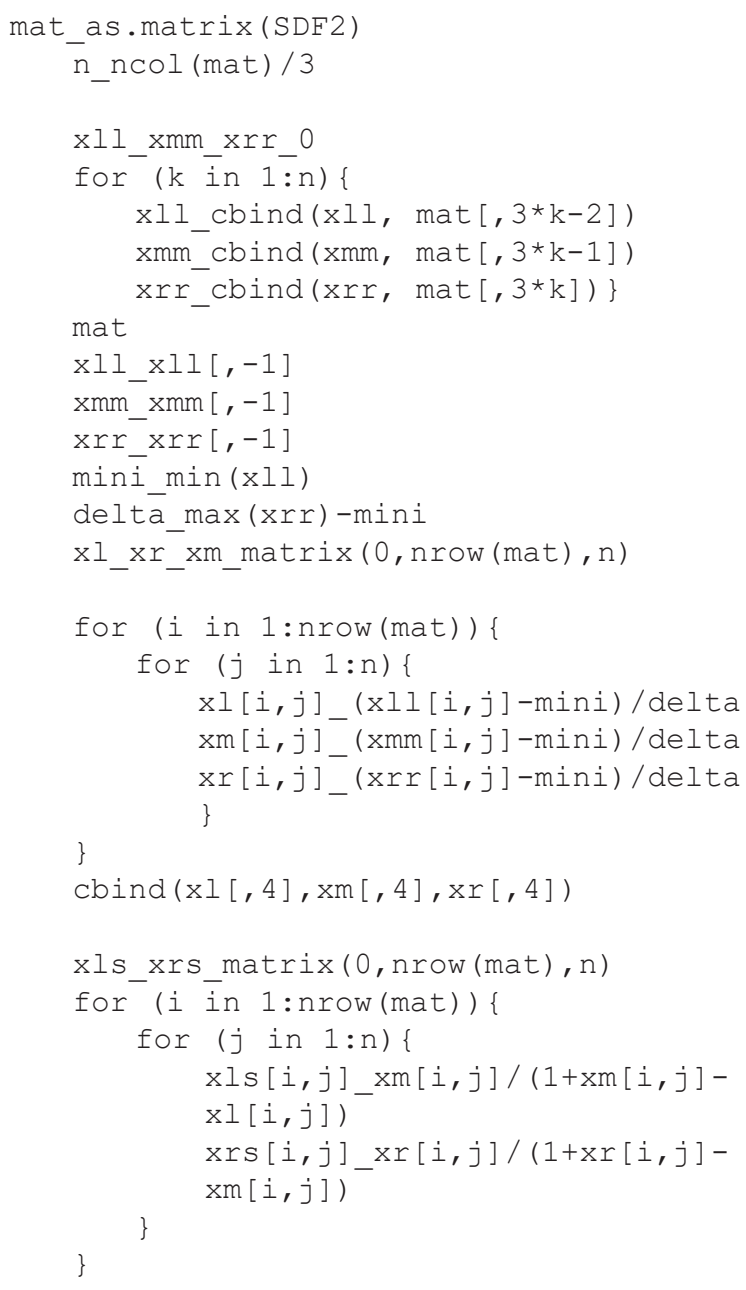

\section{B) The code of fuzzy DEMATEL method}

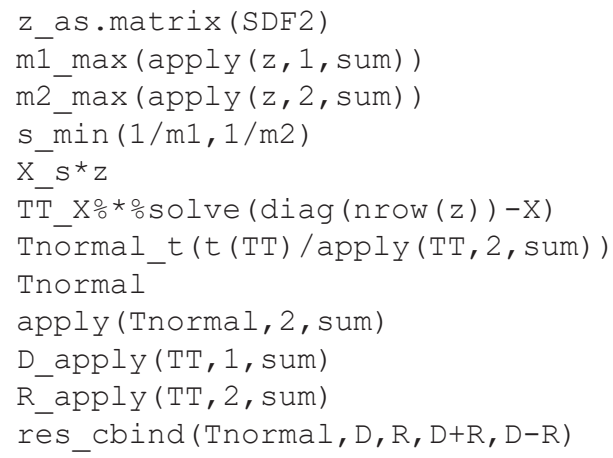

\section{C) The code of fuzzy ANP for obtaining Limited supermatrix}

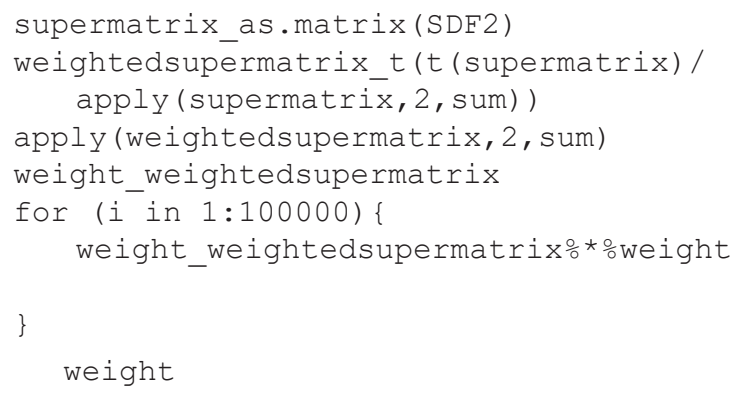

